\title{
Wild monkeys flake stone tools
}

Tomos Proffitt* (1), Lydia Luncz* (1), Tiago Falótico (2), Eduardo B Ottoni (2), Ignacio de la Torre (3), Michael Haslam (1)

\section{Affiliations}

1: Primate Archaeology Research Group, School of Archaeology, University of Oxford, Dyson Perrins Building, South Parks Road, Oxford OX1 3QY, United Kingdom

2: Institute of Psychology, University of São Paulo, São Paulo, SP 05508-030, Brazil.

3: Institute of Archaeology, University College London, 31-34 Gordon Square, London WC1H OPY, United Kingdom

* These authors contributed equally to this work. 
Our understanding of the emergence of technology shapes how we view the origins of humanity ${ }^{1,2}$. The earliest stone technology ${ }^{3}$, is recognised primarily through sharpedged stone flakes, struck from larger stone cores. However, here, we show that wild bearded capuchin monkeys (Sapajus libidinosus) in Brazil deliberately break stones, unintentionally producing recurrent, conchoidally fractured, sharp-edged flakes and cores that have all the characteristics and morphology of intentionally produced hominin tools. This behaviour is therefore no longer unique to the human lineage, providing a novel comparative perspective on the emergence of lithic technology prior to 3.3 million years ago. This discovery adds a new dimension to interpretations of the human Palaeolithic record, the possible function of early stone tools, and the cognitive requirements for the emergence of stone flaking.

Paleoanthropologists use the distinctive characteristics of flaked stone tools both to distinguish them from naturally broken stones, and to interpret the behaviour of the hominins that produced them ${ }^{4}$. Suggested hallmarks of the earliest stone tool technology include (i) controlled, conchoidal flaking ${ }^{5}$, (ii) production of sharp cutting edges ${ }^{6}$, (iii) repeated removal of multiple flakes from a single core, (iv) clear targeting of core edges, and (v) adoption of specific flaking patterns ${ }^{7}$. These characteristics underlie the identification of intentional stone flaking at all early archaeological sites ${ }^{3,5,7-12}$, as they do not co-occur under natural geological conditions.

To date, comparisons between hominin intentional stone flaking and wild primate stone tool use have focused on West African chimpanzees (Pan troglodytes verus) ${ }^{13-16}$. Nevertheless, stone breakage during chimpanzee tool use is accidental ${ }^{15}$, a result of missed hits or indirect force application during activities such as nut-cracking. The resulting stone fragments lack most of the diagnostic criteria listed above for hominin flakes ${ }^{10,17}$. Even when 
the manufacture of sharp edges was taught to captive bonobos (Pan paniscus), the resulting flaked assemblage did not replicate the early hominin archaeological record ${ }^{18}$.

The capuchins of Serra da Capivara National Park (SCNP) in Brazil use stone tools in more varied activities than any other known non-human primate, including for pounding foods, digging, and in sexual displays ${ }^{19-21}$. Bearded capuchins and some Japanese macaques (Macaca fuscata) are known to pound stones directly against each other ${ }^{22}$, however, the SCNP capuchins are the only wild primates that do so for the purpose of damaging those stones $^{19}$. This activity, which we term stone on stone (SoS) percussion, typically involves an individual selecting rounded quartzite cobbles from a conglomerate bed (active hammers), and with one or two hands striking the hammerstone forcefully and repeatedly on quartzite cobbles embedded within the conglomerate (passive hammers) (Figure 1, Extended Data 1). 


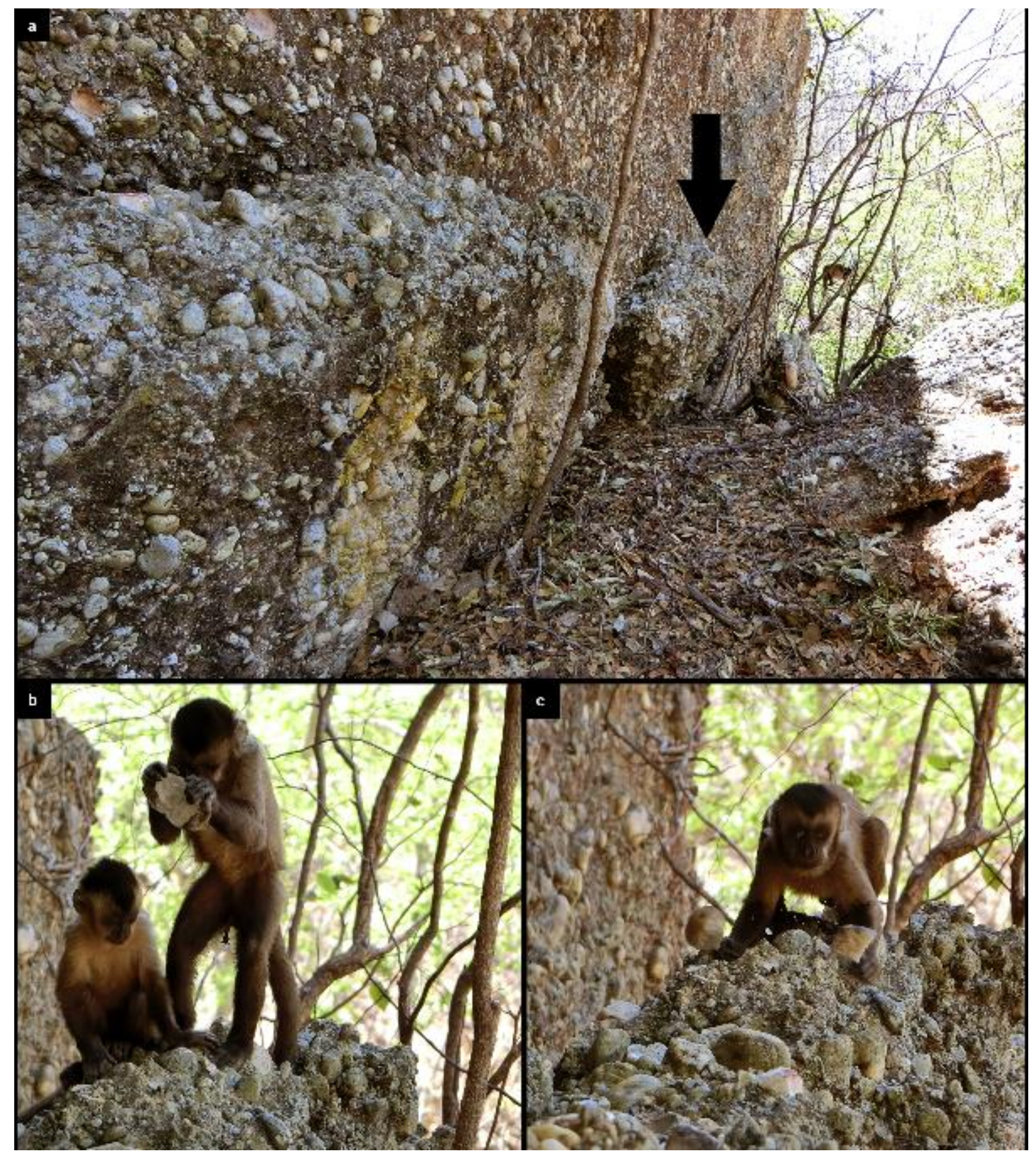

Figure 1| Wild bearded capuchin stone on stone (SoS) percussion, Serra da Capivara

National Park, Brazil. a, Conglomerate outcrop where SoS percussive behaviour of $\mathbf{b}$, and

c, was observed. b, and c, SoS percussive actions including close observation by a juvenile capuchin in $\mathbf{b}$, and stone breakage in $\mathbf{c}$. Note that the active hammer in use is part of Refit Set 6 (Supplementary Information and Extended Data 1) 
Previous observations of capuchin stone percussion indicate that this behaviour occurs in an aggressive context ${ }^{23}$. In our observations, however, the monkeys licked or sniffed the crushed passive hammers after about half of their percussion event ${ }^{19}$ (Extended Data 1), suggesting that they may be ingesting either powdered quartz or lichens. While the stones do not contain any biologically active components ${ }^{19}$, silicon is known to be an essential trace nutrient ${ }^{24}$. SCNP capuchins have also been seen to use a stone hammer to dislodge another stone from the conglomerate, with the second stone then used as a hammer for SoS percussion $^{20}$.

In addition to deliberately crushing the surface of both the active and passive hammers, the capuchins regularly unintentionally break the stones during use (Extended Data 1). In addition, we observed a capuchin purposefully place a newly fractured stone flake on top of another stone, and then strike it with a hammer in a manner resembling chimpanzee nutcracking or human bipolar reduction (Extended Data 1). Nevertheless, while the monkeys were seen to re-use broken hammerstone parts as fresh hammers, they were not observed using the sharp edges of fractured tools to cut or scrape other objects.

We collected fragmented stones immediately after capuchins were observed using them at the Oitenta site in SCNP ( $8^{\circ} 52.394 \mathrm{~S}, 42^{\circ} 37.971 \mathrm{~W}$ ) (Figure 1), as well as from surface surveys and archaeological excavation in the same area (Extended Data 2). The assemblage consists of 111 capuchin modified stone artefacts, including complete and broken hammerstones, complete and fragmented flakes, and passive hammers. We also found flaked hammerstones, which using a traditional classification would be considered flaked artefacts ${ }^{25}$ (Extended Data 3). All stones were obtained by the capuchins from conglomerates in the vicinity of their use. 
Complete hammerstones have a mean weight of $600.3 \mathrm{~g}$ (Extended Data $4 \mathrm{a})$. They possess varying degrees of percussive damage across their surfaces, including small impact points surrounded by circular or crescent scars (Supplementary Information and Extended Data 5). Broken hammerstones and flaked hammerstones comprise over a quarter of the total assemblage. Broken hammerstones are on average smaller than complete hammerstones (mean: $203.8 \mathrm{~g}$; Extended Data 4a), and some would be termed split cobbles in a hominin assemblage. Flaked hammerstones exhibit one or more conchoidal or wedge flake scars, occurring either as (i) 1-2 fortuitous scars from a natural striking platform, or as (ii) recurring unidirectional, overlapping, flakes resulting from repeated strikes on a fracture plane (Supplementary Information). Refitted hammerstones demonstrate this reduction sequence (Supplementary Information and Extended Data 8, 9). Continuous rotation and manipulation of the hammerstones during use also produces small $(<1 \mathrm{~cm})$, non-invasive, step terminating, flake scars along the edge of the striking platform, perpendicular to the flaking surface. These artefacts are indistinguishable from some archaeological examples of intentionally flaked early hominin stone cores. Using a traditional classification, the flaked hammerstones fall within the morphology of unifacial choppers ${ }^{1}$.

Complete flakes produced during SoS percussion have sharp edges, bulbs of percussion, and scars from up to three previous flake removals (Supplementary Information and Extended Data 7). A high proportion of wedge-initiated flakes occur in the early stages of reduction, evidenced by an increased frequency of cortical flakes. Conchoidal flakes, on the other hand, come from both early and later stages of reduction, with both cortical and noncortical pieces represented. Extensive refits record the production of unidirectional recurrent, conchoidal flakes following an initial forceful fracture (Supplementary Information and Extended Data 8, 9, 10). 


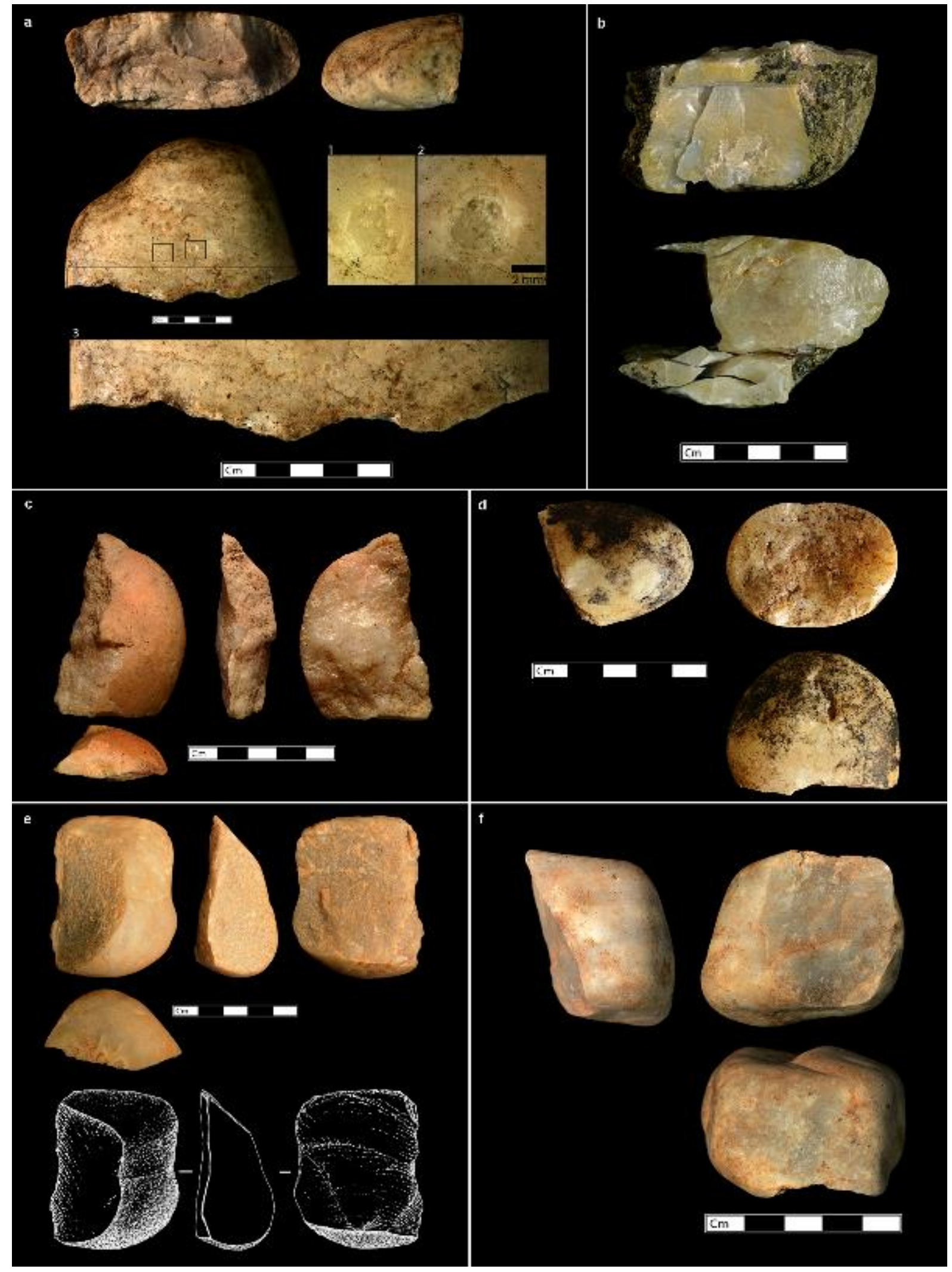

Figure 2 | Examples of flaked stones from capuchin stone on stone percussion. a,

Detail of a large, unidirectionaly flaked active hammerstone, with clear impact marks located towards the centre of the striking platform. b, Refitted active hammer (Refit Set 6; Extended 
Data 9b and Extended Data 10) illustrating recurrent unidirectional removal of at least seven flakes. $\mathbf{c}$ and $\mathbf{e}$, Examples of conchoidal flakes. $\mathbf{d}$ and $\mathbf{f}$, Examples of flaked hammerstones. Scales are in $\mathrm{cm}$, except for a $2 \mathrm{~mm}$ scale for the inset in a

Passive hammers, whether found detached from or embedded in the conglomerate, typically have a localised area of percussive damage located on a prominent surface (Figure 3). The damage includes impact points, battering marks and crushed quartz crystals and, in some cases, detached flakes or chips. The passive hammers in this study (mean: $303.7 \mathrm{~g}$, Extended Data 4a) also retain evidence of their subsequent re-use as active hammers, with impact points located on previously-embedded flat planes opposite the passive hammer damage. This use clearly occurred after the stone was dislodged from the conglomerate. Capuchin SoS tools are therefore multifunctional, with the monkeys able to repurpose stones from a passive to an active percussive role (Supplementary Information). 


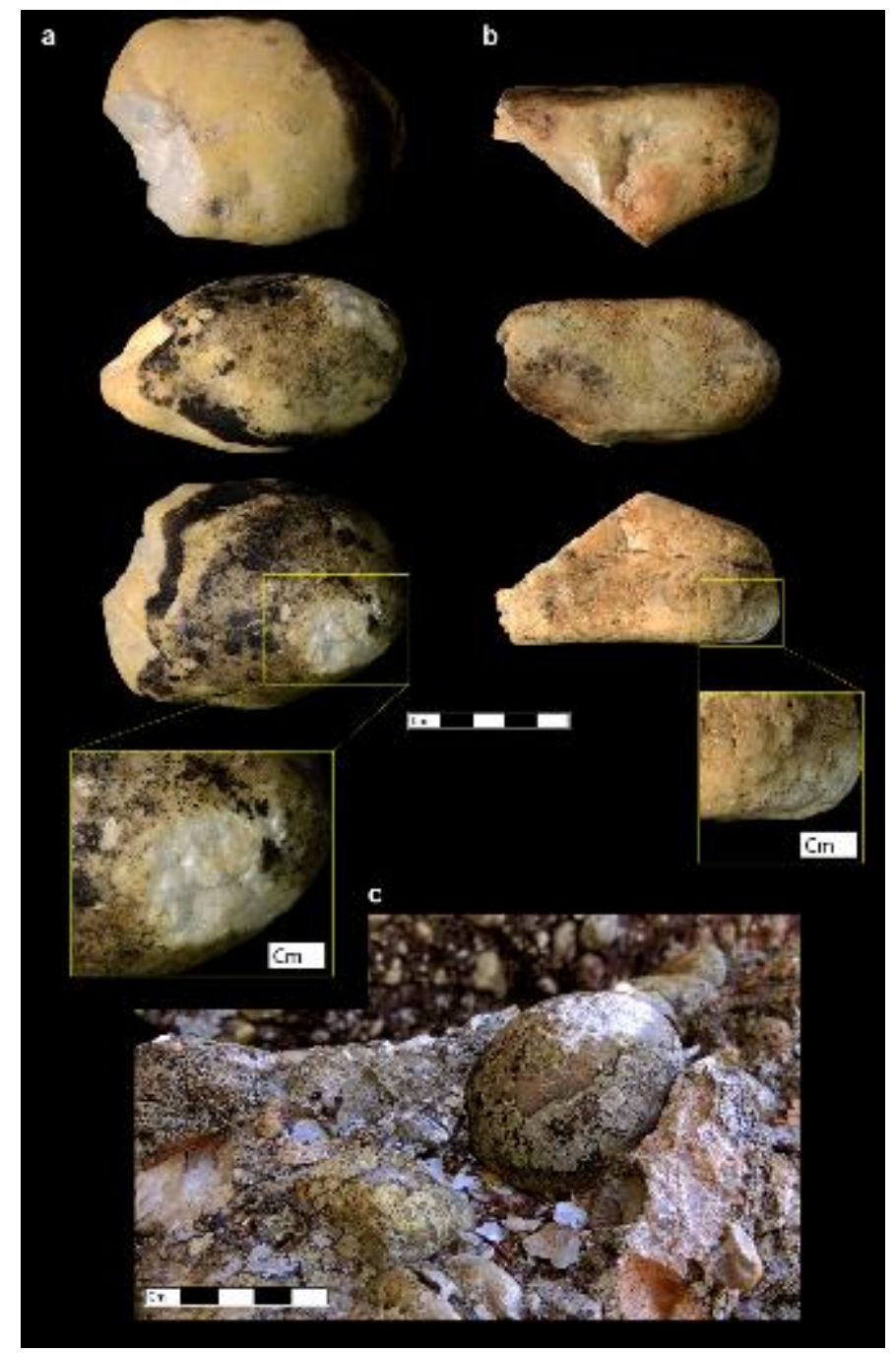

\section{Figure 3: Examples of passive hammers from capuchin stone on stone (SoS)}

percussion. $\mathbf{a}$ and $\mathbf{b}$, Passive hammers with detail of intense percussive damage. $\mathbf{c}$, Passive hammer in situ at Serra da Capivara National Park, following its observed use for SoS percussive behaviour. Note small flake fragments at the base of the passive element, resulting from active hammer flaking. Scales are in $\mathrm{cm}$

The distinctive assemblages found at stone-on-stone percussion sites will guide future archaeological investigations into the development of capuchin technology at SCNP ${ }^{26}$, and the broader Middle Pleistocene dispersal of Sapajus into northeast Brazil27. They should also assist in distinguishing human tools from capuchin artefacts where the range of these primates overlap ${ }^{12}$. Of interest beyond Sapajus behavioural evolution, SCNP capuchins 
produce stone debris through a similar technique (passive hammer) inferred from some of the earliest hominin archaeological assemblages ${ }^{3,5,11}$. The passive hammer knapping technique involves striking a hammerstone onto a passive anvil, with the desired flakes detached from the handheld stone ${ }^{11}$ (Extended Data 1). Both active and passive hominin hammers often have repeated impact marks away from the tool's edge, interpreted as evidence of poorly controlled strikes or mutli-purpose tool use ${ }^{3}$. SCNP capuchin behaviour demonstrates that these marks, and recurrent conchoidally fractured, sharp-edged flakes, can be produced entirely unintentionally.

The SCNP data provide an example of repeated conchoidal flaking that is not reliant on advanced, human-like hand morphologies and coordination ${ }^{28}$. Similarly, SoS behaviour presents an alternative to evolutionary explanations that link the origins of recurrent flake production to a change in hominin cognitive skills ${ }^{28,29}$. In the absence of supporting evidence such as cut-marked bones, we suggest that sharp edged flake production can no longer be implicitly or solely associated with intentional production of cutting flakes. Capuchin SoS percussion and simple Plio-Pleistocene stone knapping activities are equifinal behaviours in the production of flaked lithic assemblages. These findings open up the possibility that unintentional flaked assemblages may be identified in the palaeontological record of extinct apes and monkeys. In light of this possibility, criteria commonly used to distinguish intentional hominin lithic assemblages need to be refined.

No living primate is a direct substitute for extinct hominins, which varied in unknown ways from the behaviour, cognition and morphology seen in extant animals and humans ${ }^{15}$. However, capuchin SoS percussion is the only known example of intentional stone damage by a non-human primate that produces concentrated lithic accumulations. Capuchin SoS percussion flakes and flaked hammerstones fall within the range of mean dimensions for 
simple flakes and cores in the Early Stone $\mathrm{Age}^{3}$ (Supplementary Information and Extended Data 4b). If encountered in a hominin archaeological context, this material would be identified as artefactual, potentially interpreted as the result of intentional stone fracture and controlled flake production, and likely attributed to functional needs requiring the use of sharp edges.

The capuchin data add support to an ongoing paradigm shift in our understanding of stone tool production and the uniqueness of hominin technology. Within the last decade, the use ${ }^{30}$ and intentional production ${ }^{3}$ of sharp edged flakes has been shown to be no longer necessarily tied to the genus Homo. Capuchin stone on stone percussion goes a step further, demonstrating that the production of archaeologically identifiable flakes and cores, as currently defined, is no longer unique to the human lineage.

Online Content Methods, along with any additional Extended Data display items and Source Data, are available in the online version of the paper; references unique to these sections appear only in the online paper.

Supplementary Information is available in the online version of the paper.

\section{Acknowledgements}

The study was funded by a European Research Council Starting Investigator Grant (\#283959) to M.H., and São Paulo Research Foundation (FAPESP) awards to T.F. (\#2013/05219-0) and E.B.O (\#2014/04818-0). Support for fieldwork and analysis was provided by Niède Guidon and Gisele Daltrini Felice of FUMDHAM, and University College London (ERC Starting Grant \#283366). We thank Rafaela Fonseca de Oliveira for 
excavation coordination, Michael Gumert, Rafael Mora and Adrian Arroyo for comments, and Angeliki Theodoropoulou for artefact illustrations.

\section{Author Contributions}

M.H. and T.F. observed and recorded the capuchin behaviour, collected lithic material and directed excavations at Serra da Capivara National Park. T.P. conducted the technological analysis. T.P., L.L., I.D.L.T., and M.H. discussed the implications of the results. T.P. wrote the paper and supplementary online content with contributions from L.L., T.F., E.O., I.D.L.T., and M.H. T.P generated all figures, 3D models and video content, using data recorded by M.H and T.P.

\section{Author Information}

Reprints and permissions information is available at www.nature.com/reprints. The authors declare no competing financial interests. Readers are welcome to comment on the online version of the paper. Correspondence and requests for materials should be addressed to T.P. (tomos.proffitt@arch.ox.ac.uk) or M.H. (michael.haslam@arch.ox.ac.uk). 


\section{Material and Methods}

\section{Material}

The stone on stone (SoS) percussion assemblage included 111 artefacts collected from surface and archaeological capuchin activity locations in Serra da Capivara National Park (SCNP), Plauí, Brazil. The surface collection (Lasca OIT Surface; $n=60,54.1 \%$ ) was produced by capuchins observed performing SoS percussion in September 2014, at a site later designated Lasca Oitente 2 (Lasca OIT 2). The capuchins belong to the Jurubeba group, which was first studied in March $2004^{20}$. SoS activity primarily took place on a low (approximately $1 \mathrm{~m}$ high), narrow conglomerate ridge associated with a much larger conglomeratic outcrop (Figure 1; Extended Data 1). During this time a portion of the utilised assemblage dropped to the ground immediately below the activity area, and was collected once the activity ceased. Additional material was collected during surface surveys within the immediate vicinity of Lasca OIT 2, at locations where isolated conglomerate blocks were used by the same capuchin group for SoS percussion. This material was also analysed as Lasca OIT Surface.

The archaeological material comes from two excavations conducted in June 2015 (Extended Data 2), within the Jurubeba group range: Lasca OIT 1 ( $8^{\circ} 52.460 \mathrm{~S}, 42^{\circ} 37.977 \mathrm{~W}$ ) and Lasca OIT 2 ( $8^{\circ} 52.394 \mathrm{~S}, 42^{\circ} 37.971 \mathrm{~W}$ ). We excavated both sites by hand in $5 \mathrm{~cm}$ levels, and sieved all sediment through a $5 \mathrm{~mm}$ mesh. Sediments at both sites were a light brown silty sand with gravel to cobble-sized inclusions, resulting from the in situ weathering of local conglomerates. We distinguished capuchin tools from natural stones on the basis of percussion marks and flaking features as described in the main text and below. The Lasca OIT 2 excavation (Extended Data $2 b$ ) can be considered an extension of the surface material collected in 2014 from the same site. An area of $3 \mathrm{~m}^{2}$ excavated to a maximum depth of $0.5 \mathrm{~m}$ yielded 28 (25.2\%) SoS percussion artefacts at Lasca OIT 2. We excavated Lasca OIT 1 (Extended Data 2a), located 120 m southwest of Lasca OIT 2, beneath the sheer face of an approximately $7 \mathrm{~m}$ high conglomerate outcrop that showed percussion marks indicative of previous SoS activity. A total excavated area of $3 \mathrm{~m}^{2}$ to a maximum depth of 0.4 m yielded $23(20.7 \%)$ artefacts at this site. We did not find human material, such as hearths, ceramic pieces, metal objects, or ground stone at either site. Such items are ubiquitous in anthropogenic sites elsewhere in SCNP ${ }^{31}$. This absence, along with direct 
observation of capuchins creating the flaked surface assemblage, and the identical nature of the damage and size of the recovered stones to those observed in use by capuchins, rules out human production of the archaeological material.

\section{Methods}

We identified the raw material of each artefact, and performed technological classification and analysis following commonly used technological attributes ${ }^{7,9,32,33}$. For full details and definitions of the technological categories used in this analysis, see the Supplementary Information. 


\section{References}

\section{Main Text}

1. Leakey, M. D. Olduvai Gorge, Vol. 3. Excavations in Beds I and II, 1960-1963.

(Cambridge University Press, 1971).

2. Potts, R. Early hominid activities at Olduvai. (AldineTransaction, 1988).

3. Harmand, S. et al. 3.3-million-year-old stone tools from Lomekwi 3, West Turkana, Kenya. Nature 521, 310-315 (2015).

4. Panger, M. A., Brooks, A. S., Richmond, B. G. \& Wood, B. Older than the Oldowan? Rethinking the emergence of hominin tool use. Evol. Anthropol. Issues News Rev. 11, 235-245 (2003).

5. Isaac, G. L. I. Early hominids in action: A commentary on the contribution of archaeology to understand the fossil record in East Africa. Yrbk Phys Anthr. For 1975, 19-35 (1976).

6. Toth, N. The Oldowan reassessed: a close look at early stone artifacts. J. Archaeol. Sci. $12,101-120$ (1985).

7. Delagnes, A. \& Roche, H. Late Pliocene hominid knapping skills: the case of Lokalalei 2C, West Turkana, Kenya. J. Hum. Evol. 48, 435-472 (2005).

8. Semaw, S. The World's Oldest Stone Artefacts from Gona, Ethiopia: Their Implications for Understanding Stone Technology and Patterns of Human Evolution Between 2.6-1.5 Million Years Ago. J. Archaeol. Sci. 27, 1197-1214 (2000).

9. Stout, D., Semaw, S., Rogers, M. J. \& Cauche, D. Technological variation in the earliest Oldowan from Gona, Afar, Ethiopia. J. Hum. Evol. 58, 474-491 (2010).

10. De la Torre, I. Omo revisited: evaluating the technological skills of Pliocene Hominids. Curr. Anthropol. 45, 439-465 (2004).

11. Lewis, J. E. \& Harmand, S. An earlier origin for stone tool making: implications for cognitive evolution and the transition to Homo. Phil Trans R Soc B 371, 20150233 (2016). 
12. Boëda, E. et al. A new late Pleistocene archaeological sequence in South America: the Vale da Pedra Furada (Piauí, Brazil). Antiquity 88, 927-941 (2014).

13. Matsuzawa, T., Humle, T. \& Sugiyama, Y. The chimpanzees of Bossou and Nimba. (Springer Science \& Business Media, 2011).

14. Mercader, J., Panger, M. A. \& Boesch, C. Excavation of a chimpanzee stone tool site in the african rainforest. Science 296, 1452-1455 (2002).

15. McGrew, W. C. Chimpanzee material culture: implications for human evolution. (Cambridge University Press, 1992).

16. Mercader, J. et al. 4,300-year-old chimpanzee sites and the origins of percussive stone technology. Proc. Natl. Acad. Sci. U. S. A. 104, 3043-3048 (2007).

17. Pelegrin, J. in Stone knapping: The necessary conditions for a uniquely hominid behaviour. McDonald Institute Monograph Series, Cambridge (eds. Roux, V. \& Bril, B.) 23-33 (McDonald Institute monograph series, 2005).

18. Toth, N., Schick, K. \& Semaw, S. in The Oldowan: case studies into the earliest Stone Age (eds. Toth, N. \& Schick, K.) 155-222 (Stone Age Institute Press, 2006).

19. Falótico, T. \& Ottoni, E. B. The manifold use of pounding stone tools by wild capuchin monkeys of Serra da Capivara National Park, Brazil. Behaviour 153, 421-442 (2016).

20. Mannu, M. \& Ottoni, E. B. The enhanced tool-kit of two groups of wild bearded capuchin monkeys in the Caatinga: tool making, associative use, and secondary tools. Am. J. Primatol. 71, 242-251 (2009).

21. Falótico, T. \& Ottoni, E. B. Stone throwing as a sexual display in wild female bearded capuchin monkeys, Sapajus libidinosus. PloS One 8, e79535 (2013).

22. Leca, J.-B., Gunst, N. \& Huffman, M. Complexity in object manipulation by Japanese macaques (Macaca fuscata): A cross-sectional analysis of manual coordination in stone handling patterns. J. Comp. Psychol. 125, 61-71 (2011).

23. Moura, A. C. de A. Stone Banging by Wild Capuchin Monkeys: An Unusual Auditory Display. Folia Primatol. (Basel) 78, 36-45 (2007). 
24. Carlisle, E. M. Silicon as an essential trace element in ammal nutrition. Silicon Biochem. 703, 123 (2008).

25. Isaac, G. L. Koobi Fora Research Project Vol. 5: Plio-Pleistocene archaeology. (Clarendon, 1997).

26. Haslam, M. \& et al. Pre-Columbian Monkey Tools. Curr. Biol. in press, (2016).

27. Haslam, M. Towards a prehistory of primates. Antiquity 86, 299-315 (2012).

28. Kivell, T. L. Evidence in hand: recent discoveries and the early evolution of human manual manipulation. Philos. Trans. R. Soc. B Biol. Sci. 370, 20150105 (2015).

29. de la Torre, I. Insights on the technical competence of the early Oldowan. Stone Tools Evol. Hum. Cogn. 45-65 (2010).

30. McPherron, S. P. et al. Evidence for stone-tool-assisted consumption of animal tissues before 3.39 million years ago at Dikika, Ethiopia. Nature 466, 857-860 (2010).

31. Pessiss, A.-M., Martin, G. \& Guidon, N. Os Biomad e as Sociedades Huanas na PreHistoria da Regiao do Parque nacional Serra da Capivara, Brasil. Volume II-B. (2014).

32. Inizan, M.-L., Reduron-Ballinger, M. \& Roche, H. Technology and Terminology of Knapped Stone: Followed by a Multilingual Vocabulary Arabic, English, French, German, Greek, Italian, Portuguese, Spanish. 5, (Cercle de Recherches et d'Etudes Préhistoriques, 1999).

33. De la Torre, I. \& Mora, R. Technological Strategies in the Lower Pleistocene at Olduvai Beds I \& II. (2005).

34. Chavaillon, J. Essai pour une typologie du matériel de percussion. Bull. Société Préhistorique Fr. 76, 230-233 (1979).

35. Toth, N. The Stone Technologies of Early Hominids at Koobi Fora, Kenya, An Experimental Approach. (University of California, 1982). 


\section{Supplementary Online Material - Wild monkeys flake stone tools}

\section{Supplementary Information}

\section{Definition of Technological Categories}

1.1 Hammerstones. We identified hammerstones following Leakey's ${ }^{1}$ definition. They are cobbles possessing "pitting, bruising and slight shattering"1. In addition, hammerstones were separated into active and passive hammers following Chavallion's ${ }^{34}$ definitions. Active hammers are handheld cobbles used to directly strike a stationary passive hammer.

1.2 Fragmented hammerstones. A consequence of the SoS percussive behaviour is the fragmentation of active hammers, and this is the process by which the majority of the associated SoS assemblage was produced.

We identified two categories of fragmented hammerstones: broken hammerstones and flaked hammerstones. Broken hammerstones are those that have fractured either laterally or transversally due to percussive action, and exhibit little subsequent damage. Flaked hammerstones are either complete or broken active hammers which, due to subsequent percussive use, act as a core for one or more wedge or conchoidal flake detachments. Typical knapping cores are defined as blocks of "raw material from which flakes, blades, or bladelets have been struck in order to produce blanks for tools" ${ }^{32}$. In this sense, intentionality of production is inherent in the definition of a core and associated debitage ${ }^{32}$. Typical hominin cores possess a number of technological characteristics that are commonly used for identification and analysis. These include the presence of one or more knapping platforms, 
(either naturally occurring, or prepared) and one or more flaking surfaces, from which flakes are detached. Within the capuchin SoS percussion assemblage a substantial number of artefacts possess one or more flake detachments from a flaking surface and associated platform of percussion. These artefacts are unintentional by-products of the continued percussive use of both complete and broken hammerstones. It is important to note that intentional production of flakes plays no part in the use of these artefacts, and as such the term core cannot be applied. Instead the term flaked hammerstone has been used. Flaked hammerstone as used here is comparable to Isaac's ${ }^{25}$ flaked pieces, and would be classified as such if identified in an archaeological context.

1.3 Complete and fragmented flakes. Complete flakes typically possess a striking platform with associated impact point and dorsal and ventral surfaces. Fragmented flakes are distally, proximally or laterally broken.

1.4 Angular chunks and small debris. Angular chunks consist of fragmented pieces without a clear striking platform, and no differentiation between ventral and dorsal planes. Small debris includes fragmentary chips of raw material derived from larger cobbles during SoS percussion, but possessing no classifiable technological attributes.

\section{Analysed Attributes}

\subsection{Hammerstones and broken hammerstones}

We measured linear dimensions for all complete and broken hammerstones, which included maximum length $(\mathrm{mm})$, width $(\mathrm{mm})$, thickness $(\mathrm{mm})$ and weight $(\mathrm{g})$. We identified and assessed a range of technological attributes on all hammerstones, including blank type, original blank morphology, number of utilised planes, distribution of percussive damage, percussive damage surface morphology, and degree of percussive damage. In addition, the fracture type was also documented for all broken hammerstones.

\section{$2.2 \quad$ Flaked hammerstones}

We measured the linear dimensions of all flaked hammerstones following the same protocols as for complete and broken hammerstones. We also measured the maximum linear dimensions of all flake extractions larger than $10 \mathrm{~mm}$. As well as the technological 
attributes used in the analysis of broken hammerstones, we recorded a number of technological characteristics commonly used in the analysis of Plio-Pleistocene archaeological cores. These included flaked hammerstone blank type, original blank morphology, degree of percussive damage, hammerstone fracture type, flake initiation, core knapping accidents, degree of cortex coverage, and number of extractions. As all flaked hammerstones possess one or more flake removals, each piece was also classified into commonly used reduction types ${ }^{33}$, which indicate the prevailing direction and angle of flake removals.

\subsection{Complete flakes}

We measured both linear and technological dimensions for all complete flakes, including maximum length $(\mathrm{mm})$, width $(\mathrm{mm})$, thickness $(\mathrm{mm})$, and weight $(\mathrm{g})$. Technological dimensions included technological length $(\mathrm{mm})$, width $(\mathrm{mm})$ and thickness $(\mathrm{mm})$. Here we define technological length as the maximum linear dimension originating from the impact point on the knapping platform to the distal extent of the flake, technological width as the maximum measurement orthogonal to the technological length, and technological thickness as the maximum measurement perpendicular to both technological length and width. Technological attributes collected during analysis included striking platform cortex, platform morphology, platform faceting, platform shape, bulb of percussion, knapping accidents, presence of dorsal surface step scars, transversal and sagittal cross sections, dorsal surface cortex, number of dorsal extractions, dorsal extraction directionality, and Toth's flake categories $^{35}$.

\subsection{Fragmented flakes, angular chunks, and small debris}

We measured the maximum dimensions and weight of all fragmented flakes, angular chunks, and small debris in the same manner as complete flakes.

\subsection{Passive hammers}

We collected the maximum linear dimensions for all passive hammers following the same methodology applied to complete and fragmented hammerstones. In addition, the same technological attributes analysed for complete hammers were applied to passive hammers. 


\section{Lithic Analysis}

\subsection{Artefact frequencies}

SoS percussive behaviour is represented by 111 modified artefacts collected from three separate locations within SCNP. The capuchins produced all artefacts on rounded quartzite cobbles, sourced from the immediate vicinity of their original use and collection ${ }^{19}$.

Detached flakes (both complete and fragmented) are the most prevalent artefact category ( $n=44,38.98 \%$ ), with fragmented hammerstones (both flaked and broken hammerstones) ( $n=33,29.2 \%)$, and chunks ( $n=14,12.39 \%)$ also making up a substantial proportion of the assemblage. Complete hammerstones contribute $14.16 \%(n=16)$ of the assemblage (Extended Data 3).

\subsection{Hammerstones}

On average, complete hammerstones used for SoS percussion measure $103 \mathrm{~mm} \mathrm{x} 77 \mathrm{~mm} \times$ $54.5 \mathrm{~mm}$, and weigh $600.3 \mathrm{~g}$ (range 155-1500 g) (Extended Data 4a). When both broken and complete hammerstones are combined, the majority have a tabular cross section $(n=16$, $57.1 \%)$, with a smaller proportion being plano-convex $(n=10,35.7 \%)$. Only a small proportion of all hammerstones are irregular $(n=1,3.6 \%)$.

We identified percussive damage on hammerstones as percussive crushing (Extended Data 5a) and small impact points surrounded by a circular or crescent scar caused by the development of an incipient hertzian cone (Extended Data $5 \mathrm{~b}$ ). Complete hammerstones possess an overall low degree of battering, with the majority showing moderate $(n=9,56.3 \%)$ degrees of percussion damage, with less severe impact damage (very light and light) also strongly represented $(n=7,43.8 \%)$. Furthermore, the majority of hammerstones possess damage on 3 or more planes $(n=9,56.3 \%)$ with the balance $(n=7,43.8 \%)$ showing percussion damage on at least 2 separate planes. Percussive damage is typically highly clustered on at least one active surface $(n=9,60 \%)$. However, percussive damage is also dispersed across the hammerstone surfaces in a notable number of artefacts ( $n=6,40 \%)$, indicating that capuchin hammerstone use is not always highly targeted.

Hammerstone ridges, as well as horizontal and convex surfaces, all show varying degrees of percussion damage. The most common location for percussion on hammerstones is on flatter surfaces, with $75 \%(n=13)$ of all complete hammerstones possessing percussion damage on such a surface. Convex surfaces are also heavily utilised, with $62.6 \%(n=10)$ possessing percussion damage on at least one such surface. Percussive damage is less 
frequently observed along prominent ridges at $43.8 \%(n=7)$. In the majority of cases, hammerstones possess percussive damage on multiple surface morphologies $(n=11$, $68.8 \%$ ), with capuchins showing no clear single preference for utilising a specific surface morphology for percussive tasks.

\subsection{Fragmented hammerstones}

Fragmented hammerstones comprise $29.2 \%(n=33)$ of all modified material. The majority of these are classified as flaked hammerstones. Hammerstones which can be considered merely as broken specimens make up a smaller percentage of the total assemblage $(n=12$, $10.6 \%)$.

\subsection{Broken hammerstones}

On average, broken hammerstones measure $87.6 \mathrm{~mm} \times 51.4 \mathrm{~mm} \times 41.89 \mathrm{~mm}$ and weigh $203.8 \mathrm{~g}$ (Extended Data 4a). Their dimensions fall within those of complete hammerstones and flaked hammerstones, indicating no increased rate of hammerstone fracture for larger hammerstones during the percussive activity.

The majority of fractured hammerstones show percussive damage on only one surface $(n=8$, $66.7 \%)$, with the percussion damage on the whole being sparse $(n=5,41.6 \%)$ or dispersed $(n=4,33.3 \%)$, and located primarily on horizontal surfaces $(n=7,58.3 \%)$.

The type of hammerstone fracture indicates the prevailing manner in which a capuchin used the hammerstone. The majority of broken hammerstones show transverse breakages $(n=7$, $58.3 \%)$. However, close to half the sample also show lateral fractures $(n=4,41.7 \%)$. These data may indicate a marginal preference for utilising flatter surfaces, and a greater sample would help test this hypothesis.

\subsection{Flaked hammerstones}

Flaked hammerstones make up a significant proportion of the assemblage both in terms of frequency $(n=21,18.6 \%)$ and total weight $(4283 g, 22 \%)$ (Extended Data $4 a)$. Those artefacts that exhibit either individual or a series of conchoidal flake detachments are typologically and technologically indistinguishable from archaeological examples of intentional cores.

Flaked hammerstones possess mean dimensions of $71.7 \mathrm{~mm} \times 47.4 \mathrm{~mm} \times 38.7 \mathrm{~mm}$ and a mean weight of $204 \mathrm{~g}$ (range $48.9 \mathrm{~g}-1101 \mathrm{~g}$ ). Compared to the complete and broken hammerstones, there is a significant difference in all dimensions (Kruscal Wallis: $L=14.431$ (2), $p=0.001 ; \mathrm{W}=21.508(2), p=0.000 ; \mathrm{Th}=11.862(2), p=0.003$ ) and weight (Kruscal Wallis: $19.435(2), p=0.000$ ), showing a distinct reduction in size from complete hammerstones to increasingly fragmented and flaked hammerstones as percussive 
behaviour is continued past the initial breakage of the original hammerstone. When compared to previously published mean dimensions for Plio-Pleistocene archaeological cores, mean dimensions of capuchin flaked hammerstones (mean length $=71.73 \mathrm{~mm} \pm 22.6$ $\mathrm{mm}$, mean width $=47.37 \mathrm{~mm} \pm 14.93 \mathrm{~mm}$, mean thickness $=38.5 \mathrm{~mm} \pm 38.6 \mathrm{~mm}$ ) fall within the range of all Oldowan cores (mean length range $=30.5 \mathrm{~mm}-83.3 \mathrm{~mm}$, mean width range $=22.3 \mathrm{~mm}-78.3 \mathrm{~mm}$, mean thickness range $=13.5 \mathrm{~mm}-59 \mathrm{~mm}$ ), however they are notably smaller than published dimensions of cores from Lomekwi 3 (mean length $=167$ $\mathrm{mm}$, mean width $=147.8 \mathrm{~mm}$, mean thickness $=108.8 \mathrm{~mm})(\text { Extended Data } 4 \mathrm{~b})^{3}$.

We observed two distinct reduction sequences within the flaked hammerstone assemblage. The first and least common is produced on complete hammerstones $(n=4,19 \%)$. These cases exhibit either typical hammerstone flake detachments or 1-2 fortuitous flake detachments owing to the impact of a naturally occurring knapping platform $\left(<90^{\circ}\right)$ against the passive element, detaching a fully conchoidal flake.

The second and most prevalent reduction method $(n=17,81.0 \%)$, is associated with the reuse of previously broken hammerstones. In the majority of these cases, the original hammerstone has undergone a transverse $(n=13,76.5 \%)$ or longitudinal $(n=4,23.5 \%)$ wedging fracture, resulting in the production of a flat non cortical plane with roughly $90^{\circ}$ or $<90^{\circ}$ angles between it and its adjacent planes. Continued percussive activity centred on this newly created horizontal plane, in a number of cases concentrated along the margins, results in the detachment of fully conchoidal flakes around part or all of the circumference of the natural 'striking platform'. The high frequency of transverse fractures on the broken hammerstones that were subsequently flaked by the capuchins mirrors the fracture patterns observed on broken hammers. This finding suggests either a capuchin preference for using flat planes as a working surface, or a higher probability that flat active planes fracture more frequently. The resulting morphology of these flaked hammerstones closely resembles Early Stone Age cores on split cobbles, and mimic classic unifacial Oldowan choppers.

Flaked hammerstones have multiple flake removals, with the majority possessing $>3$ clear detachments ( $n=12,70.6 \%$ ). On average, flake scars measure $30.9 \mathrm{~mm} \times 20.9 \mathrm{~mm}$ in maximum dimensions, and $23.8 \mathrm{~mm} \times 28.0 \mathrm{~mm}$ when technologically orientated, indicating wide and short flake removals. Compared to the maximum dimensions of all flake removals, the results of a Mann-Whitney $U$ test show a significant difference in maximum length $(U=937, p=0.003)$ and width $(U=874.5, p=0.023)$ of flake scars compared to complete flakes. More small flake removals are evident on flaked hammerstones than were collected from the surface and archaeological assemblages, in part because some of the broken pieces fell into inaccessible crevices and down cliffs following their damage by capuchins. Capuchin 
unintentional stone reduction is not exhaustive, as seen in the high frequency of flaked hammerstones with $>50 \%$ cortical coverage $(n=14,82.4 \%)$. Interestingly, very few flaked hammerstones possess evidence of traditional flaking accidents, such as step scars or plunging removals, with only $23.8 \%(n=5)$ possessing step scars on their flaking surfaces. In fact, most flake removals terminate in clean feather terminations.

While all flake extractions associated with this behaviour are the unintentional result of percussive activity, the flakes can still be classified into a number of exploitation strategies commonly identified in late Pliocene and Pleistocene lithic assemblages ${ }^{3,9,10}$. The majority show either unifacial simple or abrupt flaking $(n=19,90.4 \%)$ from one or more cortical or non-cortical platforms. In addition, a single flaked hammerstone also exhibits radial flake detachments, caused by the frequent rotation and manipulation of the hammer during percussion.

Impacts derived from the passive hammer are often located close enough to the edge of the knapping platforms to elicit a true conchoidal fracture. In a number of cases, the resulting flake detachments can be considered as invasive and superimposed, highlighting the recurrent removal of flakes (clearly evidenced by a number of refits), which mimic Early Stone Age flake production. Nonetheless, a distinction must be made between this material and some highly exploited and refined Oldowan cores identified in the archaeological record (e.g material identified at Lokalalei $2 \mathrm{C}^{7}$ ). When flaked hammerstones are derived from previously broken hammerstones, the non-cortical knapping platform is formed through the splitting of the hammerstone cobble. Although derived unintentionally, the result is the repetitive splitting of cobbles similar to that identified in the archaeological record. In the latter instance, this behaviour has been interpreted as an intentional hominin behaviour to facilitate flake production ${ }^{7}$. Furthermore, the capuchins produce a combination of flake scars and fracture plane patterning that fall within the morphology of unifacial choppers ${ }^{1}$ (Extended Data 6).

A number of flaked hammerstones possess small $(<1 \mathrm{~cm})$, non-invasive, step terminating, flake scars along the edge of the acting knapping platform, perpendicular to the flaking surface. These removals are often associated with impact points resulting in a flake detachment from the primary flaking surface. These small flake detachments result from impacts on the flaked surface brought about by capuchins continually rotating and manipulating the hammerstone during SoS percussion. 


\subsection{Flakes}

Complete flakes are the most prevalent single artefact type associated with the capuchin SoS percussion behaviour, making up $27.4 \%(n=31)$ of the assemblage. When combined with flake fragments, the high degree of debitage production during this behaviour is apparent $(n=44,39 \%)$. Complete flakes measure on average $39.4 \mathrm{~mm} \times 26.5 \mathrm{~mm} \times 13.2$ $\mathrm{mm}$, and weigh an average of $20.5 \mathrm{~g}$ (Extended Data 4a). When technologically orientated, they possess a mean length and width of $31.6 \mathrm{~mm}$ and $44.6 \mathrm{~mm}$, indicating short removals that are slightly wider than they are long. When compared to published hominin flake dimensional data ${ }^{3}$, the mean dimensions of capuchin SoS percussion flakes (mean length $=$ $33.4 \mathrm{~mm} \pm 15.8 \mathrm{~mm}$, mean width $=26.5 \mathrm{~mm} \pm 12.4 \mathrm{~mm}$, mean thickness $=13.2 \mathrm{~mm} \pm 7.5$ $\mathrm{mm}$ ) are highly comparable to those reported for Oldowan Plio-Pleistocene hominin flakes (mean length range $=20.8 \mathrm{~mm}-40.18 \mathrm{~mm}$, mean width range $=17.8 \mathrm{~mm}-37.4 \mathrm{~mm}$, mean thickness range $=5.9 \mathrm{~mm}-13.2 \mathrm{~mm}$ ). Capuchin flakes are, however, notably smaller than reported dimensions of Lomekwian flakes (mean length $=120 \mathrm{~mm}$, mean width $=110.1 \mathrm{~mm}$, mean thickness $=43.9 \mathrm{~mm})^{3}$.

We identified three initiation types within the flake assemblage: wedging ( $n=16,54.6 \%)$, conchoidal $(n=14,45.1 \%)$ and cleavage plane fractures $(n=1,3.2 \%)$. The majority of wedge initiated flakes possess no clear bulb of percussion $(n=15,93.8 \%)$ and a relatively flat ventral surface ( $n=14,87.5 \%)$. In addition, often the impact point is crushed owing to the application of force beyond that required to detach the flake. The knapping platforms of wedge-initiated flakes are primarily non-faceted and cortical $(n=15,93.8 \%)$, with either a convex $(n=9$, $56.3 \%)$ or flat $(n=7,43.8 \%)$ morphology, preserving the outer surface of the tabular or planoconvex cobbles.

Conversely, the large majority of conchoidally produced flakes show either diffused $(n=7$, $50 \%)$ or prominent $(n=6,42.9 \%)$ bulbs of percussion, and concave $(n=7,50 \%)$ or flat $(n=5$, $35.7 \%)$ ventral surfaces. Their knapping platforms are mostly non-faceted ( $n=6,42.9 \%)$, although uni- $(n=5,35.7 \%)$ and bi-faceted $(n=3,21.4 \%)$ platforms are present. As a group, non-cortical $(n=7,50 \%)$ and $<50 \%$ cortical $(n=1,7.1 \%)$ platforms are prevalent, with fewer possessing cortical $(n=5,35.7 \%)$ and $>50 \%$ cortical $(1,7.1 \%)$ platforms.

Complete flakes regularly have clear dorsal scars, with about a third possessing a single previous removal ( $n=10,32.3 \%), 16.1 \%(n=5)$ two previous removals, and a single $(3.2 \%)$ flake has 3 previous extractions. These dorsal surface scars indicate a total of 23 previous extractions, for which the direction could be ascertained for $60.9 \%(n=14)$. The directional patterns indicate that the majority possess a previous single unidirectional detachment $(n=7$, $50 \%)$. However, longer sequences of unidirectional removals were also identified $(n=4$, 
28.5\%). In addition to unidirectional exploitation, both bidirectional $(n=1,7.1 \%)$ and transversal $(n=2,14.2 \%)$ reduction is also observable to a lesser extent, indicating, in some cases, a degree of 'core' / active hammer rotation during percussion.

Overall, the majority of flakes produced by capuchins during SoS behaviour are of a high quality, as shown by clear impact points, a lack of flaking accidents and uninterrupted feather terminations (Extended Data 7). Furthermore, a high number of the non-fully cortical flakes possess either triangular $(n=11,35.5 \%)$ or trapezoid $(n=5,16.1 \%)$ transversal cross sections as well as triangular $(n=10,32.3 \%)$ or trapezoid $(n=2,6.5 \%)$ sagittal cross sections, commonly associated with recurrent reduction of $\operatorname{cores}^{33}$.

The production of conchoidal and wedging flakes associated with SoS behaviour is clearly derived from different stages in the use of hammerstones. Although both flake initiations occur throughout the use-life of a stone on stone percussion hammerstone, a high proportion of wedging initiated flakes occur in the early stages of reduction, resulting in an increased frequency of Toth's flake categories stage I $(n=9,56.3 \%)$ and II $(n=5,31.3 \%)$. Conchoidal flakes, on the other hand, are associated with both early and later stages of reduction, with Toth's flake categories stages I ( $n=3,21.4 \%)$ and II $(n=4,28.6 \%)$, and IV $(n=1,7.1 \%)$ and V $(n=6,42.9 \%)$ represented.

\subsection{Passive hammers}

We collected two passive hammers in this study, accounting for $1.8 \%$ of the modified assemblage. The underrepresentation of this element compared to active hammers is a consequence of their use context, with passive hammers embedded in a conglomerate matrix ${ }^{19}$. As such, unless the capuchin dislodges the passive hammer from the conglomerate, this artefact type is unavailable for detailed analysis. The passive hammers described in this report were detached by capuchins during SoS percussion.

The passive hammers measure on average $87.8 \mathrm{~mm} \times 61.2 \mathrm{~mm} \times 44.3 \mathrm{~mm}$, and weigh $303.7 \mathrm{~g}$. Technologically, they are characterised by the presence of a highly localised area of percussive damage measuring on average $27.4 \mathrm{~mm} \times 21.3 \mathrm{~mm}$, located on a prominent convex surface. The damage consists of intense battering and crushing of the quartz crystals, coupled with, in some cases, the detachment of spontaneous removals.

Both passive elements also retain evidence of their use as active SoS hammerstones. They have a number of percussive impact points located on flat horizontal planes opposite the location of passive hammer damage, as well as a transverse fracture. Their use as active hammers must have occurred once the passive element became dislodged from the conglomerate, as the hammerstone impact points are located on a part of the cobble that 
would have been inaccessible when the stone was embedded in the conglomerate. These multifunctional elements suggest that there is a fluidity to capuchin SoS behaviour, with one element being re-used as a different element in the same activity.

\section{Refit analysis}

Ten refits sets were identified, totalling 26 pieces or $23.4 \%$ of the assemblage. Three refit sets (6 artefacts) represent broken hammerstones and illustrate simple transverse fractures associated with percussive action onto a flat plane of the hammerstone. Seven refit sets (20 pieces), however, represent the reduction sequence of flaked hammerstones, and illustrate the unintentional production of flakes by capuchin monkeys (Extended Data 7 and 8).

\subsection{Refit Set 1 (2 pieces)}

Refit Set 1 represents at least two unidirectional, invasive flake detachments removed from the same cortical striking platform. Percussive force was applied to a relatively flat cortical surface (Plane A) of a tabular cobble. A point located close to the intersecting edge between Plane $A$ and $B$ was struck with enough force to detach a substantial, invasive plunging flake. The dorsal surface of this flake detachments preserves a single uni-directional large flake scar detached from the same direction, using Plane $A$ as the knapping platform. The exploitation of this flaked hammerstone can be classified as unifacial abrupt (Extended Data 7a).

\subsection{Refit Set 2 (2 pieces)}

Refit Set 2 represents three unidirectional removals. All detachments are derived from a single cortical striking platform, with the resulting flaked hammerstone falling within a unifacial chopper classification. As is common for the majority of flaked hammerstones, the sequence of removals began with the initial transverse fracture of a plano-convex hammerstone. This was caused by a centrally located impact on a relatively flat cortical plane. This fragmentation was followed by two subsequent impacts on Plane A, located along the edge of the intersection between Planes $\mathrm{C}$ and $\mathrm{B}$ with Plane $\mathrm{A}$. These flake removals are invasive, unidirectional, and detached in a left to right order. All flake detachments identified on this flaked hammerstone are associated with clear and well defined impact points (Extended Data 7b). 


\subsection{Refit Set 3 (2 pieces)}

Refit Set 3 records the removal of two separate flakes, and illustrates the detachment of both conchoidal and wedging initiated flakes from the one hammerstone. As the flake scars for each removal do not overlap the order of removal is unknown.

Both flake removals, evidenced by a single refitted wedge initiated flake and a flake scar of a conchoidal detachment, are associated with the same striking platform, a cortical, relatively flat surface of the cobble (Extended Data 7c).

\subsection{Refit Set 4 (2 pieces)}

Refit Set 4 represents at least three flake removals, as well as the initial fracture of an active hammer. In an archaeological context this artefact would be classified as a chopper.

Following the initial transverse fracture of a plano-convex cobble, evidenced by an impact point and crushing on Plane B2, the newly created non-cortical facet of one half of the hammer was utilised as the active percussion surface. During this process two series of flake removals occurred. As the flake scars from these series do no overlap, the order of removals is unknown. The first flake series is represented by two flake scars located on Plane B2, the result of removing two uni-directional, overlapping flakes. The second series is represented by a single, refitted, cortical, invasive flake from Plane $B$. All flakes identified in this sequence possessed non-cortical striking platforms (Extended Data 7d).

\section{5 Refit Set 5 (4 Pieces)}

Refit Set 5 exemplifies the process of recurrent hammerstone fracture during SoS percussive behaviour. The blank for this hammerstone is a tabular quartzite cobble, with rounded margins and flat horizontal planes.

The initial breakage of this stone is not recorded by the remaining pieces or removal scars. However, it is clear that percussive force was applied to both a flat plane (Plane A) and an undulating transversal plane (Plane B2). At an unknown point during this behaviour the cobble fragmented transversally into two roughly equally sized pieces. Subsequently, both halves of the cobble were further utilised as active hammerstones, resulting in further fragmentation of each piece.

The larger of the two pieces (Half A) continued to be used as a hammerstone, with an impact located on Plane $B$, towards the centre of the rounded transversal margin, detaching a substantial wedge-initiated flake removal that spanned the entire length of the core. This removal possesses a clear impact point, slightly crushed due to the force of the hammer blow, no bulb of percussion and a flat ventral surface. Continued use of the remaining 
hammer fragment centred on the newly created non-cortical plane, evidenced by multiple impact points across the surface, as well as a small degree of chipping located around the circumference of Plane $\mathrm{C}$ (the previous flaking surface). No further removals were elicited from the hammerstone during this use.

During subsequent use of the smaller hammerstone fragment (Half $B$ ), the hammer was reoriented, moving the active surface to Plane B, where a small number of clear impact points attest to repeated highly localised impacts. This action resulted in the removal of a substantial conchoidally initiated flake, from Plane C2. This removal possessed a crushed impact point, a diffused bulb of percussion and a concave ventral surface. Following this detachment, the hammerstone was again re-oriented, moving the active plane from Plane $B$ to plane $\mathrm{A} 2$, and resulting in a small step terminating flake removal from $\mathrm{C} 2$. This small flake is not present in the refit set, however, it produced a clear flake scar. A subsequent reorientation of the hammerstone, moving the active plane form Plane A2 to Plane B2, resulted in a small irregular flake detachment from Plane C2. A final re-orientation moved the active surface from plane B2 to Plane $\mathrm{C} 2$, where at least two impacts were located close to the intersecting edge between Plane C2 and B2, resulting in the detachment of two very small, non-invasive removals. Due to extensive re-orientation of the hammerstone during its use, the capuchins have unintentionally produced a final flake configuration that mimics radial exploitation of Early Stone Age cores (Extended Data 7a).

\subsection{Refit Set 6 (6 pieces)}

Refit Set 6 includes the most extensive sequence of flake detachments (at least seven removals) identified within the SoS percussion assemblage, with flake detachments grouped into two series of removals separated by a re-orientation of a plano-convex hammerstone.

A transverse fracture of the hammerstone during use created a flat, non-cortical facet on one half (Plane A). This facet acted as a striking platform for the first series of flake detachments (6 flakes). Five of the flakes in this series are detached from the same flaking surface (Plane B). All flakes are unidirectional, overlapping, and detached with a minimal degree of rotation of the striking platform. Each flake possesses a fully non-cortical striking platform and evidence of at least one previous flake scar. A single flake is also detached from the opposite plane (Plane B2), although this flake does not overlap with the remaining pieces so its position in the reduction sequence is not known. The first flake series ends with the splitting of the remaining hammerstone blank (Figure 1c), evidenced by a fracture of Plane $\mathrm{C} 2$. The hammerstone was then re-oriented, with the active surface moving from Plane $A$ to Plane B2. This resulted in the detachment of a single flake which spanned the entire length of Plane A. 
This refit sequence illustrates the recurrent unintentional detachment of invasive flakes often associated with capuchin SoS percussive behaviour, and exemplifies the similarities of this lithic assemblage with intentional Early Stone Age simple core and flake technologies (Extended Data 7b).

\subsection{Refit Set 7 (2 Pieces)}

Refit Set 7 is the most complete example of re-use of split hammerstones during capuchin SoS percussion. It records the exploitation of newly fractured flat surfaces as active percussive surfaces. A plano-convex cobble used as a hammerstone fractured transversally due to repeated impacts towards the centre of the slightly convex surface. During this fracture, a significant degree of crushing and shatter was produced, evidenced by a substantial void surrounding the impact that separated the cobble in two.

Once the cobble was split, the newly created, flat, non-cortical facets were used separately as active percussive surfaces. Half $A$ exhibits a unidirectional abrupt reduction sequence, consisting of a single large, invasive removal and three smaller flake detachments from Plane B. The removals slightly overlap each other, with the non-cortical facet acting as the striking platform for all four. Half $B$ exhibits the same reduction sequence, with two unidirectional, invasive flakes detached from plane $\mathrm{C} 2$, with the non-cortical facet (Plane A) acting as the striking platform.

This refit sequence closely mimics the intentional splitting of a rounded cobble in order to produce an advantageous flaking angle, with each half subsequently exploited to varying degrees. This type of flaking strategy is well documented within the archaeological assemblages of the Early Stone Age $^{9}$ (Extended Data 7c). 


\section{Extended Data}

Extended Data 1 | Video footage of stone on stone percussive behaviour in wild capuchins, Serra da Capivara National Park. Time stamp 00:10 - Use of quartzite hammerstone refitted in Refit Set 6. Time stamp 00:19 and 02:30 - Examples of hammerstone fracture during use. Time stamp 03:09 - Placement of detached flake on a passive hammer in a behaviour closely resembling hominin bipolar knapping 


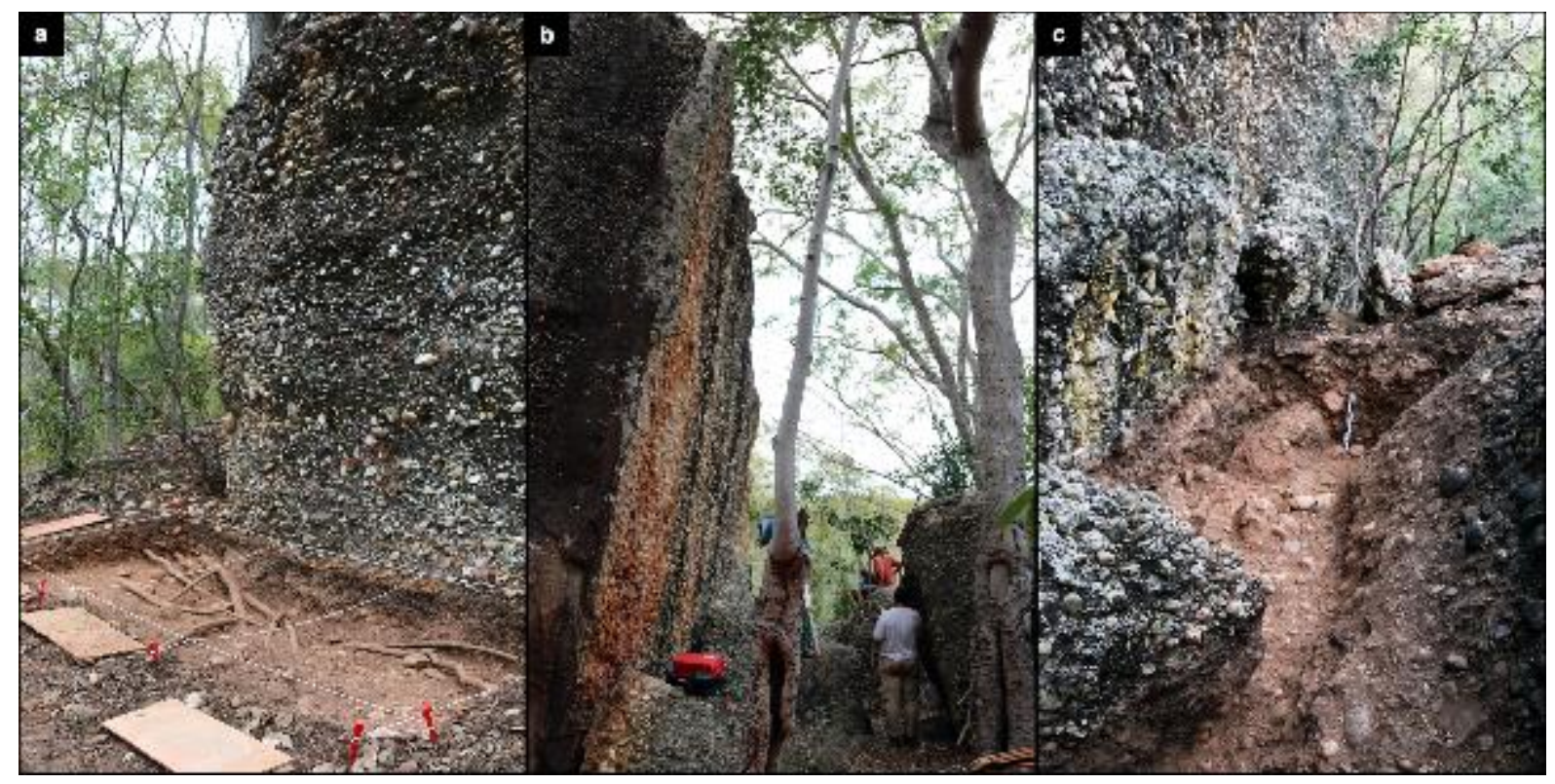

Extended Data 2 | Archaeological excavation of wild capuchin stone-on-stone (SoS) percussion sites, Serra da Capivara National Park. a, Lasca OIT1 excavation, each square is $1 \times 1 \mathrm{~m}$. $\mathbf{b}$, The approach to Lasca OIT2, which is located to the right of the conglomerate cliff face. c, Lasca OIT2 excavation, note the low conglomerate ridge to the left, on which capuchins were observed performing SoS activities; the scale is $30 \mathrm{~cm}$ (see also Figure 1) 


\begin{tabular}{|c|c|c|c|c|c|c|c|c|c|c|c|c|c|c|c|c|}
\hline \multirow[b]{4}{*}{ Techno logical Category } & \multicolumn{16}{|c|}{ Assemblage } \\
\hline & \multicolumn{2}{|c|}{$\begin{array}{l}\text { Lasca OT } \\
\text { Surface }\end{array}$} & \multicolumn{2}{|c|}{$\begin{array}{l}\text { Lasca OT } 1 \\
\text { Excavation }\end{array}$} & \multicolumn{2}{|c|}{$\begin{array}{l}\text { Lasca OT } 2 \\
\text { Excavation }\end{array}$} & \multicolumn{2}{|c|}{ Total } & \multicolumn{2}{|c|}{$\begin{array}{l}\text { Lasca OT } \\
\text { Surface }\end{array}$} & \multicolumn{2}{|c|}{$\begin{array}{l}\text { Lasca Oा } 1 \\
\text { Excavation }\end{array}$} & \multicolumn{2}{|c|}{$\begin{array}{l}\text { Lasca Oा } 2 \\
\text { Excavation }\end{array}$} & \multicolumn{2}{|c|}{ Total } \\
\hline & \multicolumn{8}{|c|}{ Frequency } & \multicolumn{8}{|c|}{ Total Weight $(g)$} \\
\hline & $\mathrm{N}$ & $\%$ & $\mathrm{~N}$ & $\%$ & $\mathrm{~N}$ & $\%$ & $\mathrm{~N}$ & $\%$ & $\mathrm{~N}$ & $\%$ & $\mathrm{~N}$ & $\%$ & $\mathrm{~N}$ & $\%$ & $\mathrm{~N}$ & $\%$ \\
\hline Complete Hammerstone & 0 & 0.0 & 8 & 34.8 & 8 & 28.6 & 8 & 14.4 & 0 & 0.0 & 4602 & 58.1 & 5002 & 612 & 9605 & 51.7 \\
\hline Broken Hammerstone & 4 & 6.7 & 2 & 8.7 & 6 & 21.4 & 2 & 0.8 & 697.9 & 279 & 570.4 & 7.2 & 898 & 23.2 & 386 & $\mathbb{7 . 0}$ \\
\hline Flaked Pieces & 0 & 8.7 & 4 & $\mathbb{7} .4$ & 7 & 25.0 & 21 & 8.9 & 297 & 518 & 2154 & 27.2 & 832.5 & 0.2 & 4283 & 23.0 \\
\hline Complete Flake & $\theta$ & 31.7 & 7 & 30.4 & 5 & 7.9 & 31 & 27.9 & 288.4 & 11.5 & 87.1 & 2.1 & 79.5 & 22 & 635 & 3.4 \\
\hline Fragmented Flake & 2 & 20.0 & 1 & 4.3 & 0 & 0.0 & $B$ & 11.7 & 41.8 & 1.7 & 27 & 0.3 & 0 & 0.0 & 68.8 & 0.4 \\
\hline Chunk & $B$ & 21.7 & 0 & 0.0 & 1 & 3.6 & 14 & 2.6 & 78.3 & 7.1 & 0 & 0.0 & 51.1 & 0.6 & 229.4 & 12 \\
\hline Small Debris & 2 & 3.3 & 0 & 0.0 & 0 & 0.0 & 2 & 1.8 & 14 & 0.1 & 0 & 0.0 & 0 & 0.0 & 14 & 0.0 \\
\hline Passive Element & 0 & 0.0 & 1 & 4.3 & 1 & 3.6 & 2 & 18 & 0 & 0.0 & 398.3 & 5.0 & 209.1 & 2.6 & 607.4 & 3.3 \\
\hline Total & 60 & 100 & 23 & 100 & 28 & 100 & 111 & 00 & 2505 & 00 & 799 & 00 & $8 \pi 2$ & 00 & 8595 & 00 \\
\hline
\end{tabular}

Extended Data 3 | Capuchin stone on stone (SoS) assemblage, Serra da Capivara

National Park. Absolute and relative frequencies, and total weights $(\mathrm{g})$, of technological categories identified in each SoS assemblage 


\begin{tabular}{|c|c|c|c|c|c|c|c|c|c|c|c|c|c|c|c|c|c|}
\hline \multirow{3}{*}{\begin{tabular}{|c} 
A \\
$\begin{array}{c}\text { Techno logical } \\
\text { Category }\end{array}$
\end{tabular}} & \multirow[b]{3}{*}{ Measure } & \multicolumn{16}{|c|}{ Assemblage } \\
\hline & & \multicolumn{4}{|c|}{ Lasca Or Surface } & \multicolumn{3}{|c|}{ Lasca Oח 1} & \multirow[b]{2}{*}{ St.Dev } & \multicolumn{4}{|c|}{ Lasca Or 2} & \multicolumn{4}{|c|}{ Total } \\
\hline & & $M$ in & $\operatorname{Max}$ & Mean & St.Dev & $M$ in & $\operatorname{Max}$ & Mean & & $M$ in & $\operatorname{Max}$ & Mean & St.Dev & $M$ in & $\operatorname{Max}$ & Mean & St.Dev \\
\hline Hammerstone & M axLength (mm) & - & - & - & - & 75.00 & 29.00 & 01.5 & 9.35 & 6170 & 149.50 & 04.89 & 27.9 & 6170 & 149.50 & 03.02 & 22.88 \\
\hline & MaxWidth (mm) & - & - & - & - & 53.90 & 93.70 & 77.8 & 2.02 & 48.80 & 28.40 & 76.90 & 24.56 & 48.80 & 26.40 & 77.03 & 8.68 \\
\hline & M axThickness (mm) & - & - & - & - & 39.70 & 74.90 & 54.63 & 1105 & 40.00 & 74.80 & 54.34 & 14.30 & 39.70 & 74.80 & 54.48 & 2.35 \\
\hline & Weight (g) & - & - & - & - & 28150 & 924.20 & 575.30 & 23189 & 55.40 & 869.00 & 625.28 & 469.54 & 85.40 & 589.00 & 600.29 & 358.67 \\
\hline Broken Hammerstone & M axLength (mm) & 48.8 & 92.58 & 77.33 & 20.24 & 75.0 & 0170 & 88.40 & 8.81 & 50.90 & 08.0 & 94.8 & $22 . \pi$ & 48.6 & 08.0 & 87.60 & 20.72 \\
\hline & MaxWidth (mm) & 30.91 & 6186 & 43.65 & 3.92 & 43.60 & 67.0 & 55.35 & 8.62 & 28.00 & 76.20 & 55.25 & 8.29 & 28.00 & 76.20 & 5140 & 521 \\
\hline & MaxThickness (mm) & 8.87 & 42.87 & 34.46 & 1103 & 42.0 & 57.60 & 49.85 & 0.96 & 14.00 & 80.90 & 44.8 & 7.01 & 14.00 & 60.90 & 4189 & 14.49 \\
\hline & Weight $(g)$ & 37.80 & 288.30 & $\pi 4.48$ & 02.87 & 87.40 & 383.00 & 285.20 & 38.31 & 28.90 & 604.90 & 38.25 & 94.21 & 26.90 & 604.90 & 283.82 & 62.03 \\
\hline Flaked Pieces & M axLength (mm) & 42.97 & 81.52 & 64.81 & 2.22 & 85.50 & 137.50 & 0123 & 24.45 & 43.00 & 01.40 & 64.76 & 2138 & 42.00 & 37.50 & 71.73 & 22.56 \\
\hline & M axWidth (mm) & 35.52 & 57.01 & 44.98 & 6.94 & 4130 & 99.50 & 67.08 & 24.52 & 32.00 & 47.00 & 39.53 & 5.48 & 32.00 & 99.50 & 47.37 & 14.93 \\
\hline & MaxThickness (mm) & 23.38 & 45.29 & 35.79 & 8.48 & 33.90 & 77.80 & 58.33 & 8.11 & 22.50 & 43.80 & 32.64 & 7.87 & 22.50 & 77.80 & 38.65 & 3.39 \\
\hline & Weight (g) & 48.90 & 247.00 & 29.69 & 53.44 & 138.70 & 10100 & 538.40 & 42.77 & 62.60 & 285.40 & 18.93 & 79.28 & 48.90 & 10100 & 203.95 & 237.45 \\
\hline Complete Flakes & M axLength (mm) & 14.80 & 70.98 & 34.95 & 8.69 & 29.90 & 63.60 & 44.34 & 11.7 & 30.20 & 65.80 & 49.70 & 0.72 & 14.80 & 70.98 & 39.45 & 8.80 \\
\hline & MaxWidth (mm) & 6.00 & 45.70 & 22.48 & 11.72 & 23.70 & 44.70 & 3154 & 8.02 & 8.50 & 52.40 & 34.68 & 5.39 & 6.00 & 52.40 & 28.49 & 2.42 \\
\hline & MaxThickness (mm) & 1.00 & 27.56 & 2.03 & 7.34 & 6.90 & 24.90 & 3.57 & 6.54 & 11.0 & 33.50 & 8.94 & 9.32 & 180 & 33.50 & B. 7 & 7.46 \\
\hline & Weight $(g)$ & .0 & 44.70 & 8.8 & 8.6 & 4.80 & 59.20 & 23.87 & 23.79 & 9.90 & 08.60 & 35.90 & 4151 & .0 & 08.60 & 20.48 & 23.65 \\
\hline Fragmented Flakes & M axLength (mm) & 13.04 & 41.75 & 21.32 & 9.49 & 79.30 & 79.30 & 79.30 & - & - & - & - & - & 3.04 & 79.30 & 25.78 & 8.47 \\
\hline & M axWidth (mm) & 7.05 & 24.42 & 13.37 & 4.93 & 28.60 & 28.60 & 28.60 & - & - & - & - & - & 7.05 & 28.60 & 14.54 & 6.33 \\
\hline & M axThickness (mm) & 3.71 & 9.92 & 6.96 & 4.64 & 14.60 & 14.60 & 14.60 & - & $\cdot$ & $\cdot$ & - & - & 3.71 & 9.92 & 7.55 & 4.93 \\
\hline & Weight $(g)$ & .40 & 28.00 & 3.48 & 7.8 & 27.00 & 27.00 & 27.00 & - & - & - & - & - & .40 & 27.00 & 5.29 & 9.48 \\
\hline Chunk & M axLength (mm) & 2.63 & 57.31 & 28.74 & B.33 & - & - & - & - & 70.40 & 70.40 & 70.40 & - & 2.63 & 70.40 & 29.88 & $\pi .32$ \\
\hline & M axWidth (mm) & 9.89 & 55.32 & 9.48 & 2.39 & - & - & - & - & 38.00 & 38.00 & 38.00 & - & 9.89 & 55.32 & 20.81 & 2.89 \\
\hline & MaxThickness (mm) & 7.01 & 33.54 & 13.60 & 7.38 & - & - & - & - & 25.00 & 25.00 & 25.00 & - & 7.01 & 33.54 & 14.41 & 7.72 \\
\hline & Weight $(g)$ & .70 & 83.00 & 3.72 & 24.0 & - & - & - & - & 51.0 & 510 & 510 & - & .70 & 83.00 & 8.39 & 25.22 \\
\hline Small Debris & M axLength (mm) & 14.03 & 14.38 & 1421 & 25 & - & - & - & - & - & - & - & - & 14.03 & 14.38 & 14.21 & 25 \\
\hline & MaxWidth (mm) & 6.22 & 8.38 & 7.29 & 1.51 & - & - & - & - & - & - & - & - & 6.22 & 8.36 & 7.29 & 1.51 \\
\hline & MaxThickness (mm) & 5.23 & 8.11 & 6.67 & 2.04 & - & - & - & - & - & - & - & - & 5.23 & 8.11 & 6.67 & 2.04 \\
\hline & Weight (g) & .80 & 80 & .70 & .14 & - & - & - & - & - & - & - & - & .60 & .80 & .70 & .14 \\
\hline Passive Hammers & M axLength (mm) & - & - & - & - & 90.20 & 90.20 & 90.20 & - & 85.3 & 85.3 & 85.3 & - & 85.30 & 90.20 & 87.75 & 3.46 \\
\hline & MaxWidth $(\mathrm{mm})$ & - & - & - & - & 68.70 & 68.70 & 68.70 & - & 53.7 & 53.7 & 53.7 & - & 53.70 & 68.70 & 6120 & 0.61 \\
\hline & MaxThickness (mm) & - & - & - & - & 50.50 & 50.50 & 50.50 & - & 38.1 & 38.1 & 38.1 & - & 38.0 & 50.50 & 44,30 & 8.77 \\
\hline & Weight (g) & - & - & - & - & 398.30 & 398.30 & 398.30 & - & 209.1 & 209.1 & 209.1 & - & 209.0 & 398.30 & 303.70 & 33.78 \\
\hline NaturalUnmodified & M axLength (mm) & - & - & - & - & - & - & - & - & 84.20 & 93.90 & 89.05 & 6.86 & 84.20 & 93.90 & 89.05 & 6.86 \\
\hline & M axWidth (mm) & - & - & - & - & - & - & - & - & 78.30 & 82.00 & 80.15 & 2.62 & 78.30 & 82.00 & 80.5 & 2.62 \\
\hline & MaxThickness (mm) & - & - & - & - & - & - & - & - & 35.70 & 44.0 & 39.90 & 5.94 & 35.70 & 44.0 & 39.90 & 5.94 \\
\hline & Weight (g) & - & - & - & - & - & - & - & - & 271.50 & 463.40 & 387.45 & 35.69 & 27150 & 463.40 & 387.45 & 135.69 \\
\hline B & & & & & Length & $(\mathrm{mm})$ & & & Width ( & (mm) & & & Thicknes & $5 s(\mathrm{~mm})$ & & & \\
\hline & Site & $\begin{array}{c}\begin{array}{c}\text { Age } \\
(\mathrm{Mal})\end{array} \\
\end{array}$ & $\mathrm{N}$ & Mean & Std & Min & $\operatorname{Max}$ & Mean & Std & $M$ in & $\operatorname{Max}$ & Mean & Std & $M$ in & $\operatorname{Max}$ & & \\
\hline & & & & & & & Flakes & & & & & & & & & & \\
\hline & LOM 3 & 3.3 & 28 & 20 & 48.8 & $\theta$ & 205 & 10.1 & 40.7 & $\theta$ & 85 & 43.9 & 23.4 & 6 & 90 & & \\
\hline & OGS7 & 2.6 & 73 & 39.1 & 14.3 & $B$ & 80 & 37.1 & 4.1 & 13 & 74 & 2.7 & 5.07 & 3 & 28 & & \\
\hline & EGD & 2.6 & 14 & 37.38 & 5.34 & 14 & 78 & 34.63 & 3.74 & 14 & 78 & 3.8 & 626 & 3 & 33 & & \\
\hline & EGR & 2.6 & 62 & 34.5 & 2.84 & 8 & 68 & 35.55 & 13.23 & $\theta$ & 66 & 2.3 & 5.76 & 4 & 30 & & \\
\hline & AL894 & 2.38 & 048 & 35.9 & 23.63 & 6 & 134 & 25.07 & $\square .57$ & 2 & 08 & 7.98 & 6.4 & 1 & 45 & & \\
\hline & LA2C & 2.34 & 500 & 38 & 5 & 2 & 96 & 35 & 14 & 7 & 28 & 11 & 5 & 3 & 28 & & \\
\hline & Omo57 & 2.34 & 44 & 24.75 & 0.546 & 0 & 58 & 20.36 & 6.851 & 0 & 44 & 7.73 & 4.008 & 1 & 8 & & \\
\hline & Omo 23 & 2.34 & 10 & 20.8 & 7.495 & 7 & 50 & ד.79 & 6.485 & 6 & 38 & 5.9 & 2.792 & 1 & 8 & & \\
\hline & DK & $>1.84$ & 15 & 40.8 & 14.803 & 8 & 111 & 37.41 & 1126 & $\pi$ & 71 & 11.89 & 5.404 & 4 & 29 & & \\
\hline & FLKZinj & $\begin{array}{l}176- \\
184\end{array}$ & 25 & 36.78 & 2.13 & B & 82 & 32.88 & 11.59 & 4 & 78 & 11.51 & 5.45 & 4 & 38 & & \\
\hline & SCNP & $\mathrm{N} / \mathrm{A}$ & 31 & 33.5 & 15.8 & 14.8 & 71 & 26.49 & 12.42 & 6 & 52.4 & 13.2 & 7.46 & 1.6 & 33.5 & & \\
\hline & & & & & & & Cores & & & & & & & & & & \\
\hline & LOM 3 & 3.3 & 83 & 87 & 23.4 & 132 & 280 & 147.8 & 23.1 & 90 & 20 & 08.8 & 21.8 & 61 & 70 & & \\
\hline & OGS7 & 2.6 & 7 & 44.14 & 3.68 & 28 & 67 & 59 & 8.54 & 45 & 70 & 37 & 8.2 & 22 & 49 & & \\
\hline & EGD & 2.8 & 8 & 83.33 & 0.34 & 69 & 05 & 60.9 & 9.8 & 44 & 80 & 45.27 & 2.36 & 30 & 69 & & \\
\hline & EGR & 2.6 & 7 & 74.45 & 8.72 & 58 & 93 & 59.73 & 8.06 & 49 & 77 & 43.73 & 77.4 & 25 & 53 & & \\
\hline & AL894 & 2.36 & 38 & 75.01 & 30.32 & 9.31 & 138.3 & 55.33 & 22.54 & 2.21 & 94.9 & 35.87 & 8.1 & 7.92 & 78.2 & & \\
\hline & $\mathrm{LA}_{2} \mathrm{C}$ & 2.34 & 70 & 66 & 8 & 39 & 23 & 52 & 14 & 32 & 95 & 32 & 2 & 2 & 78 & & \\
\hline & Omo 57 & 2.34 & 7 & 37.4 & 8.81 & 25 & 52 & 28.8 & 7.313 & 22 & 40 & 6.5 & 4.721 & $\pi$ & 24 & & \\
\hline & Omo 23 & 2.34 & 11 & 30.5 & 2.93 & $\pi$ & 56 & 22.27 & 8.88 & $B$ & 42 & 3.5 & 4.569 & 9 & 24 & & \\
\hline & DK & $>1.84$ & 69 & 67.93 & 9.46 & 30 & 17 & 62.78 & 7.992 & 25 & 00 & 48.25 & 14.435 & 8 & 81 & & \\
\hline & FLK Zinj (lava only) & $\begin{array}{l}1.76- \\
1.84\end{array}$ & 49 & 76.35 & 2.57 & 53 & 95 & 78.85 & 8.28 & 49 & 12 & 59 & 2.3 & 37 & 87 & & \\
\hline & SCNP & $\mathrm{N} / \mathrm{A}$ & 21 & 71.7 & 22.56 & 42 & 138 & 47.37 & 14.93 & 32 & 99.5 & 38.7 & 13.39 & 22.5 & 77.8 & & \\
\hline
\end{tabular}




\section{Extended Data 4 | Capuchin stone on stone (SoS) assemblage, Serra da Capivara}

National Park. a, Dimension data for all technological categories identified in this study. b, Metric comparison of SCNP capuchin SoS percussion flakes and flaked hammerstones with hominin Plio-Pleistocene flake and core dimensions. Data and table adapted from Harmand et al (2015) 


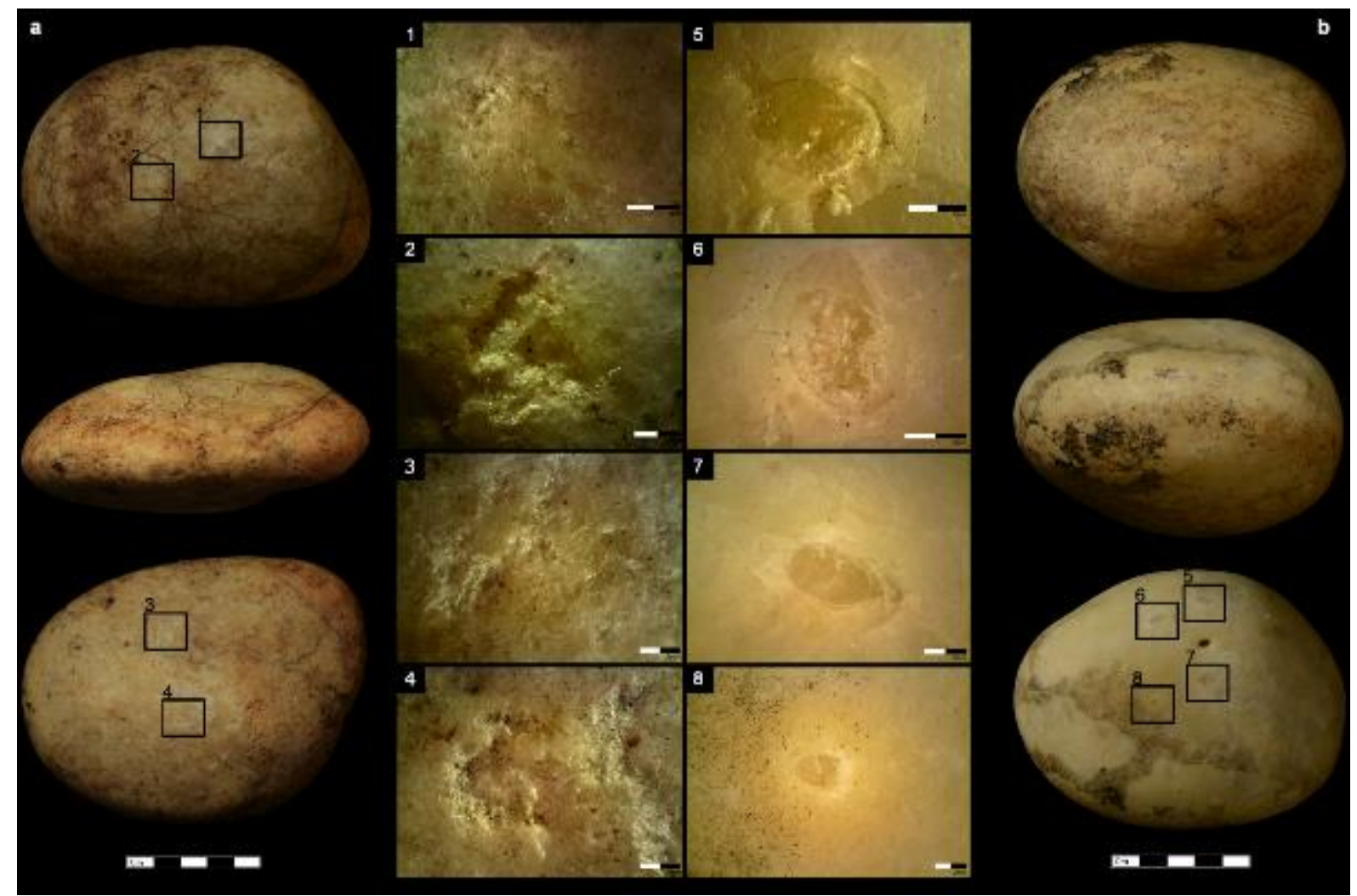

Extended Data 5 | Capuchin stone on stone assemblage, Serra da Capivara National

Park. Examples of active hammers. a, Crushing impacts on multiple surfaces of an active hammer. b. Examples of impact points and associated circular hertzian fractures on the surface of an active hammer. Scales are in cm, except for inset scales, which are in $\mathrm{mm}$ 


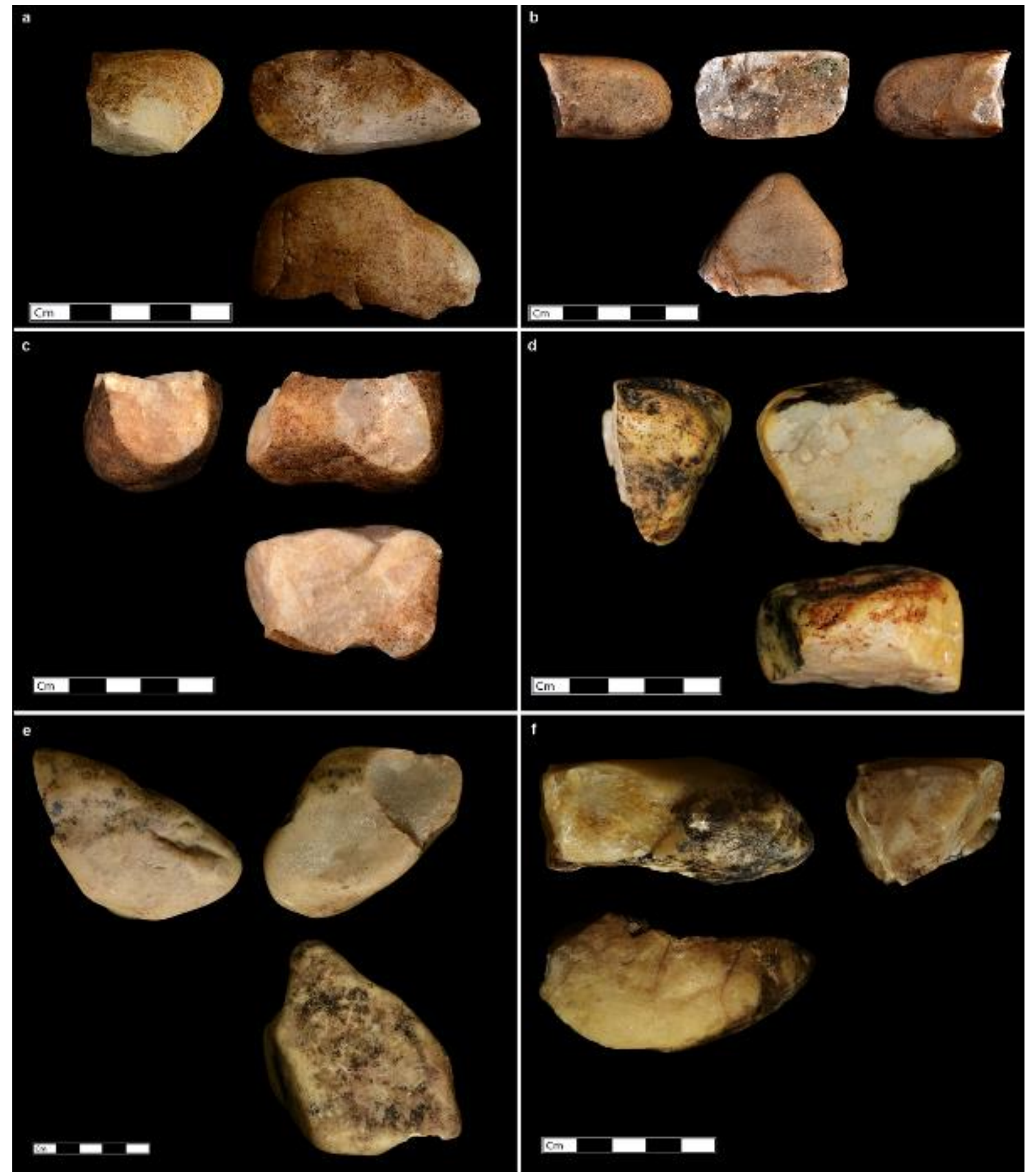

Extended Data 6 | Capuchin stone on stone (SoS) assemblage, Serra da Capivara National Park. Examples of SoS flaked hammerstones. a and c, Flake detachment following a transverse active hammer fracture. $\mathbf{b}$, Unintentional radial reduction of flaked hammerstone. $\mathbf{d} \mathbf{- f}$, Examples of complete active hammers with scars of fortuitous flakes. Scales are in $\mathrm{cm}$ 


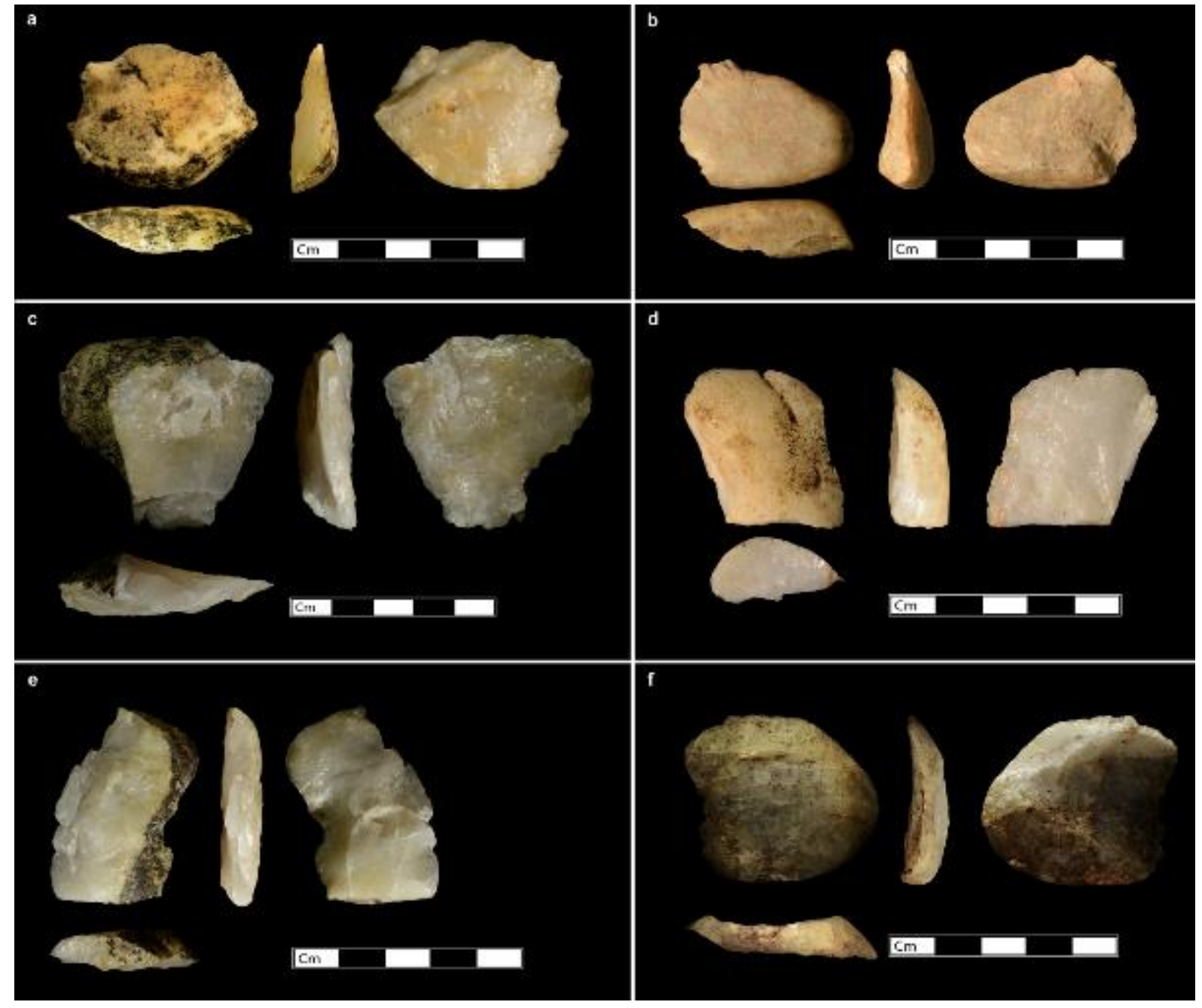

Extended Data 7 | Capuchin stone on stone (SoS) assemblage, Serra da Capivara

National Park. a - f, Examples of complete flakes detached during capuchin SoS percussion. Scales are in $\mathrm{cm}$ 


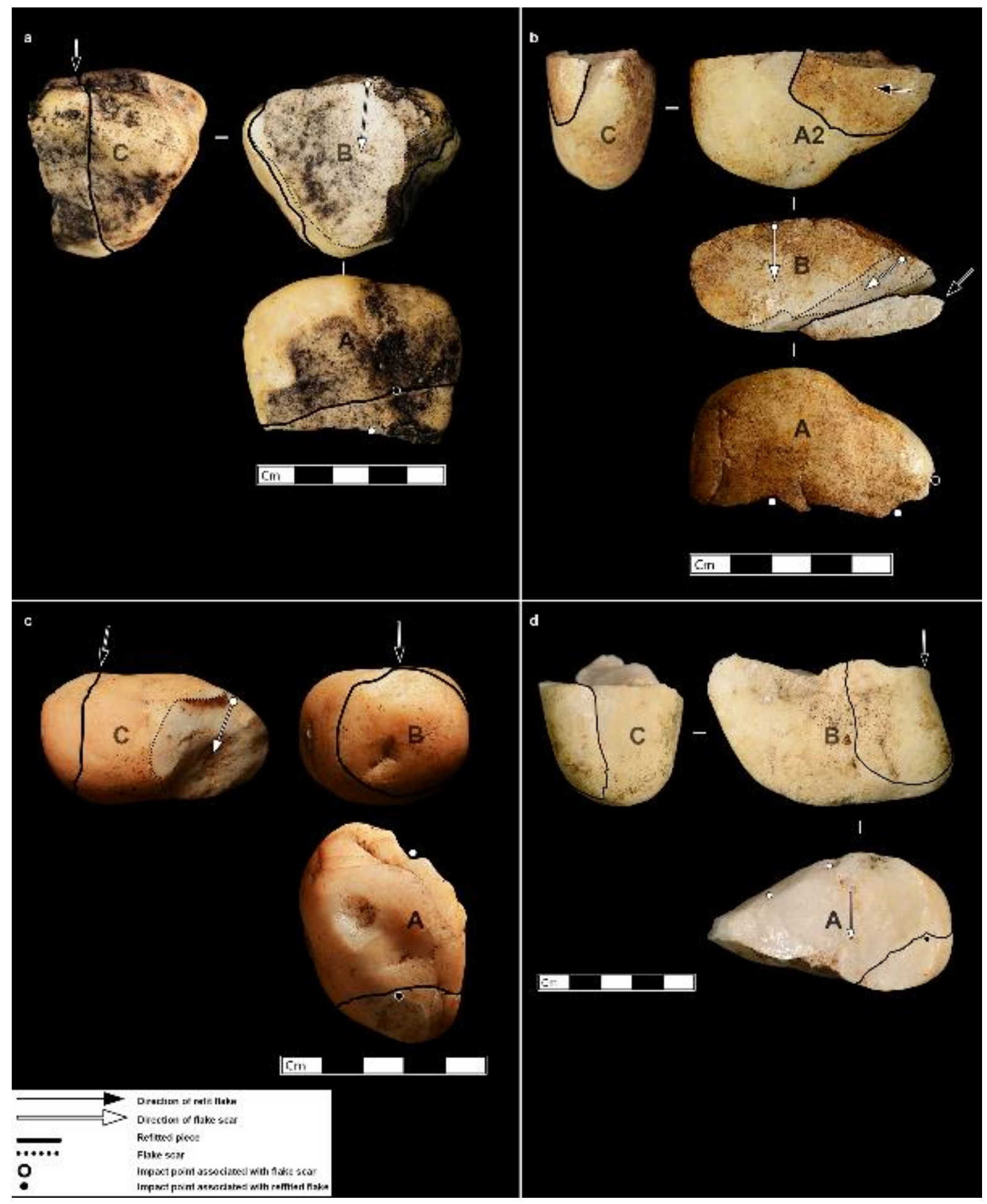

Extended Data 8 | Capuchin stone on stone (SoS) assemblage, Serra da Capivara National Park. Refits of flaked hammerstones showing the repeated detachment of unidirectional flakes. a, Refit Set 1 (Artefact numbers JC13, JF7). b, Refit Set 2 (Artefact numbers 225102a, 225102b). c, Refit Set 3 (Artefact numbers 224881a, 224881b). d, Refit Set 4 (Artefact numbers JF3, JC5). Scales are in cm 


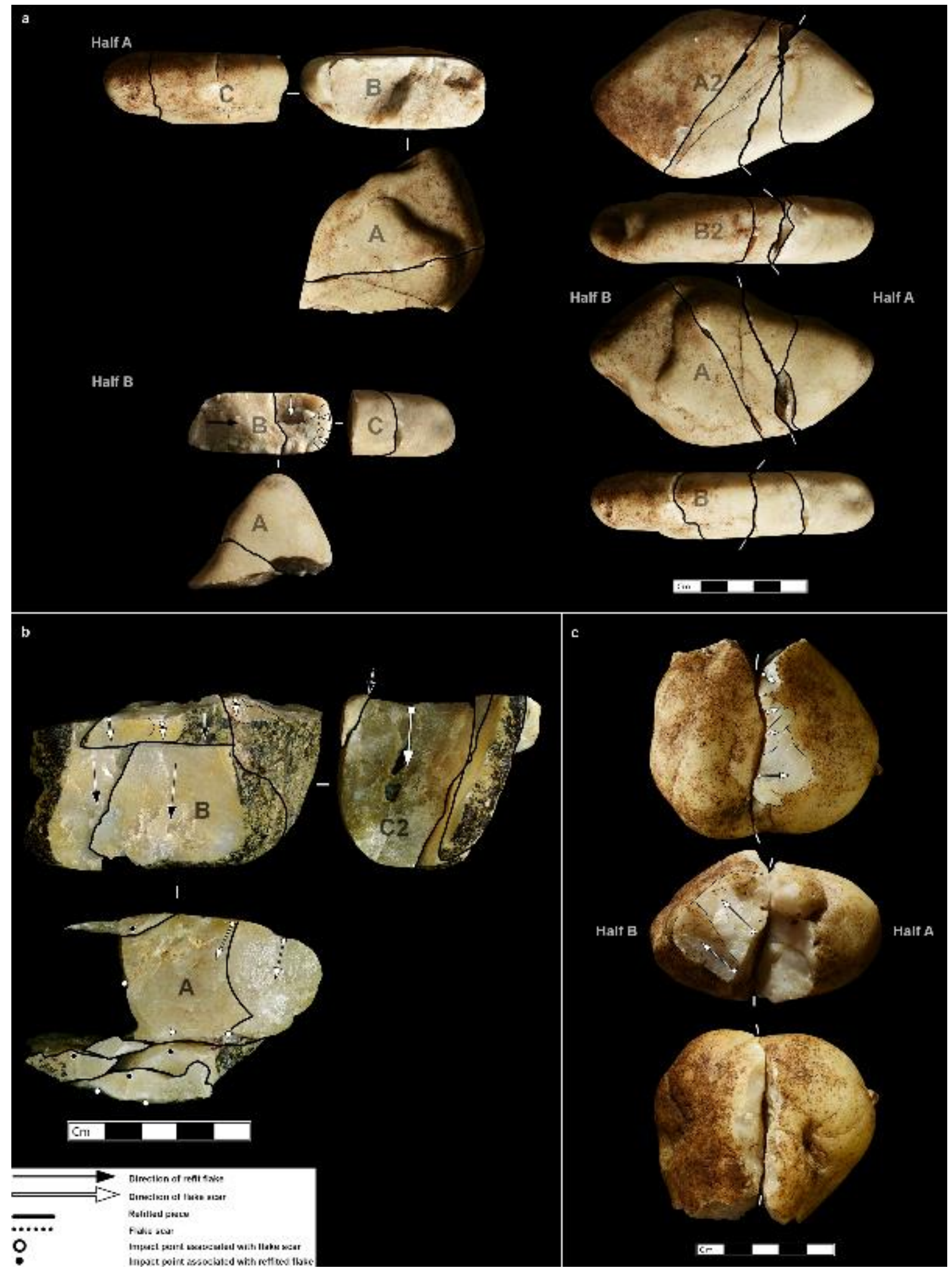


Extended Data 9 | Capuchin stone on stone (SoS) assemblage, Serra da Capivara National Park. Refits of flaked hammerstones showing the repeated detachment of unidirectional flakes and continued use of broken active hammers. a, Refit Set 5 (Artefact numbers JC11, JC12, JF23, JF1). b, Refit Set 6 (Artefact numbers JC6, JF2, JF14, JF4, JF8) (See also Extended Data 10). c, Refit Set 7 (Artefact numbers JC4, JC10). Scales are in $\mathrm{cm}$ 
Extended Data 10 | Capuchin stone on stone assemblage, Serra da Capivara National Park. Video of 3D model and reconstruction of reduction sequence for Refit Set 6, indicating the recurrent detachment of invasive flakes from a single hammerstone and examples of other flaked hammerstones and flakes 